\title{
Portfolio implications of systemic crises *
}

\author{
Erik Kole ${ }^{\dagger}$ \\ Kees Koedijk $k^{\ddagger}$ \\ Marno Verbeek $\S$ \\ Dept. of Financial Management, RSM Erasmus University, Rotterdam, The Netherlands
}

May 25, 2005

*The authors thank Raman Uppal, Hans Dewachter, Mathijs van Dijk, Nadja Guenster, Ben Jacobsen and seminar participants at the NAKE research day 2004, Tilburg University, Maastricht University and Erasmus University Rotterdam for valuable comments. Earlier drafts of the paper have been circulated under the title "The effects of systemic crises when investors can be crisis ignorant".

$\dagger$ Corresponding author. Address: P.O.Box 1738, 3000 DR Rotterdam, The Netherlands. Tel.: +31 (0)10 40813 58. Fax.: +31 (0)10 40890 17. E-mail: ekole@rsm.nl.

$\ddagger$ Koedijk is also at CEPR.

$\S$ Verbeek is also at the Econometric Institute, Erasmus University Rotterdam. 


\title{
Portfolio implications of systemic crises
}

\begin{abstract}
Systemic crises can have grave consequences for investors in international equity markets, because it causes the risk-return trade-off to deteriorate severely for a longer period. In this paper we propose a novel approach to include the possibility of systemic crises in asset allocation decisions. By combining regime switching models with Merton (1969)-style portfolio construction, our approach captures persistence of crises much better than existing models. Our analysis shows that incorporating systemic crises has a large impact on asset allocation decisions, while the costs of ignoring such crises are substantial. For an expected utility maximizing US investor, who can invest globally these costs range from $1.13 \%$ per year of his initial wealth when he has no prior information on the likelihood of a crisis, to over $3 \%$ per month if a crisis occurs with almost certainty. If a crisis is taken into account, the investor allocates less to risky assets, and particularly less to emerging markets, being most prone to a crisis. An investor facing short selling constraints withdraws completely from equity markets if the likelihood of a crisis increases.
\end{abstract}

Key words: asset allocation, systemic risk, international finance, regime switching JEL classification: G11, G15, F30, C51 


\section{Introduction}

Systemic crises can wreak havoc on national and international financial systems, making these crises an important issue for study. De Bandt and Hartmann (2000) and Dow (2000) provide excellent surveys on the characteristics and causes of systemic crises for the different financial markets, including banking, currency, credit and equity markets. In this article we focus on the consequences of systemic crises for investors in international equity markets. International investors suffer from the deterioration of the risk and return characteristics, as systemic crises exhibit a sharp drop in returns, an upswing in volatilities and a rise of the correlations between financial markets on a global scale. Evidence of this behavior has been based on the October 1987 stock market crash, and the crises that originated from the emerging markets in the 1990s (e.g. the Mexican crisis of 1994, the Asian crisis of 1997 and the Russian crisis of 1998). ${ }^{1}$ Due to their irregular and rare occurrence, standard models that investors use to support their asset allocation decisions typically fail to account for systemic crises, resulting in suboptimal international asset allocations.

The implications of systemic crises for equity portfolios have been studied by Das and Uppal (2004), who conclude that they are limited. However, their approach assumes that a systemic crises is a short-lived event that is hardly persistent. On the contrary, recent crises and their aftermaths have lasted several months, indicating persistence. If the riskreturn trade-off deteriorates for a longer period, the impact of systemic crises for investors will be more severe. In order to include possible persistence, we propose to investigate this issue by means of a regime switching model in the style of Ang and Bekaert (2002), which we combine with optimal portfolio construction as set out by Merton $(1969,1971)$. This approach allows us to model the behavior of asset returns on a regime by regime basis, making it both simple and flexible. Formulating and solving the asset allocation problem

\footnotetext{
${ }^{1}$ For research directly aimed at the October 1987 crash we refer to Roll $(1988,1989)$, Bertero and Mayer (1990) and King and Wadhwani (1990). Calvo and Reinhart (1996) discusses the Mexican crisis, Kaminsky and Schmukler (1999) and Baig and Goldfajn (1999) investigate the Asian crisis, while Kaminsky and Reinhart (2002) cover the Asian and Russian crises. A more general overview is given in De Bandt and Hartmann (2000).
} 
in continuous time ensures analytical tractability.

We distinguish among two strategies that a utility-maximizing investor can adopt to solve his asset allocation problem: a crisis conscious and a crisis ignorant strategy. The crisis conscious strategy includes a systemic crises as a distinct regime in which all markets encounter a shock, while the crisis ignorant strategy does not. For both strategies, we construct optimal portfolios. By comparing the portfolios we assess the implications and importance of a systemic crisis. For a US-based global investor, who can invest in stock markets in the US, Europe, Japan, Hong Kong, Thailand, Korea and Brazil, and a riskless asset, we find that the crisis conscious strategy leads to a reduction of the investments in risky assets and a shift to countries less prone to a crisis. A small probability of a crisis (of say 5\%) already causes these adjustments, and they quickly become more pronounced if the probability increases. Ignoring a crisis is costly, as the investor requires a certainty equivalent return of $1.13 \%$ per year as a compensation if he has no information on the ex-ante probability of a crisis. If the investor knows with almost certainty that a crisis occurs, this compensation can easily exceed $3 \%$ per month.

We make several contributions to the literature investigating the influence of extreme returns and regime switches on asset allocation. We extend the analysis of Das and Uppal (2004) in three important aspects. First, our model is better able to capture the persistence of a crisis, because we include a systemic crisis as a distinct regime in a regime-switching model, while they incorporate it by adding a perfectly correlated jump to a geometric Brownian motion. ${ }^{2}$ Second, we analyze the impact of systemic crises in a dynamic setting, which can adapt to changes in the behavior of asset prices. Third, our model without a crisis is more realistic, as the model proposed by Das and Uppal implies a normal distribution with constant means and variances. We also extend the work of Liu et al. (2003) by showing

\footnotetext{
${ }^{2}$ In a related paper, Das and Uppal (2003) also consider a regime switching model to allow for stronger persistence and conclude that it does not change their main conclusions. However, the degree of persistence they consider is fairly low compared to our analysis. For higher levels of persistence systemic crises are likely to have more severe consequences, which is also indicated by the result in Das and Uppal (2003) that the effects of systemic crises are increasing and convex for increasing levels of persistence.
} 
the effects of systemic crises on diversification, while their model is limited to a univariate setting with one risky asset only. Our finding that persistence is an important aspect of systemic crisis is consistent with their results. Our approach is complementary to Ang and Bekaert $(2002,2004)$, who consider international asset allocations in a regime-switching framework, as we use a similar framework to concentrate on the effects of systemic crises. Because of the severity of the crisis regime, we find larger effects of regime switches on diversification. As another extension to their work we show how the resulting allocation problem can be solved in continuous time.

In a broader sense our study can be seen as an investigation of the hypothesis that diversification advantages fail to be realized due to increasing correlations during market downturns, such as systemic crises. This claim has been put forward by various authors ${ }^{3}$, but it is not clear how strong this effect is. Ang and Chen (2002) conclude that the costs of ignoring increasing correlations during bear markets are substantial, but Ang and Bekaert (2002) find that diversification advantages remain present. In our approach, an increase in correlations is inherent in a crisis ${ }^{4}$. If the probability with which a crisis hits increases, diversification possibilities erode rapidly and cause large divestments. If the investor faces short sales constraints, he completely withdraws from equity markets.

The outline of the paper is as follows. In Section 2 we discuss how the crisis conscious and crisis ignorant strategies produce optimal portfolios and how the portfolios can be compared. Section 3 presents the actual design of the study, including the data. We discuss the estimation results in section 4 , and derive and and compare the allocations produced by the different strategies in section 5. Section 6 concludes.

\footnotetext{
${ }^{3}$ See, for instance, Boyer et al. (1999); Loretan and English (2000); Longin and Solnik (2001); Campbell et al. (2002); Ang and Chen (2002); Ang and Bekaert (2002); Campbell et al. (2003).

${ }^{4}$ It is widely discussed whether the tendency of markets to move downward together is a form of contagion or can be explained by joint shocks (see Forbes and Rigobon, 2002; Corsetti et al., 2005).
} 


\section{A crisis conscious and a crisis ignorant strategy}

The investor can adopt two strategies to construct an optimal portfolio: a crisis conscious and a crisis ignorant strategy. As their main ingredients, both strategies contain a model for the return process and a formulation of the asset allocation problem as their main ingredients. In both cases, a Markov regime switching model is applied to describe the return process. We prefer regime switching models to models with jump components, since the first offer more flexibility to capture heteroskedasticity and fat tails ${ }^{5}$. The difference between the strategies is the presence of distinct crisis regimes in the model employed by the crisis conscious strategy. The model in the crisis ignorant strategy can be interpreted as a restricted version of that in the crisis conscious strategy.

We assume that the investor formulates and solves his asset allocation problem in an expected utility, continuous time framework. Because of the continuous time approach, the problem has a closed-form solution, contrary to the numerical approach of Ang and Bekaert (2002). The different models for the return process will lead to different allocations for the two strategies. Because the investor constructs his asset allocation under expected utility, we can determine the economic importance of those differences by calculating the certainty equivalent return needed to compensate the investor if he incorrectly uses the crisis ignorant strategy.

In the first subsection, we discuss the models for the return process. In the next one, we formulate and solve the investor's asset allocation problem. Subsection 3 shows how the continuous time return process in the model of the asset allocation problem should be constructed to make it consistent with the predictions resulting from the Markov regime switching models. In subsection 4 we derive the compensation (as certainty equivalent return) that the investor requires if he incorrectly adopts the crisis ignorant strategy. We

\footnotetext{
${ }^{5}$ Timmermann (2000) shows that regime switching models can imply higher order moments that are more in accordance with the fat tails in asset returns that have been documented by Longin (1996). Hamilton and Susmel (1994) show that regime switching models can capture the autoregressive conditional heteroskedasticity in returns.
} 
conclude by showing how the differences between the allocations of the crisis conscious and crisis ignorant strategies can be explained.

\subsection{Regime switching models for the return process}

We start with the more general model that is used in the crisis conscious strategy, and consider the restricted version in the crisis ignorant strategy subsequently. The general model for the return process consist of several regimes. The behavior of the return process within a regime corresponding to a normal period is made up of basic components, while its behavior within a regime corresponding with a systemic crisis contains both basic and crisis components. By choosing this setup, a systemic crisis can be clearly interpreted as a simultaneous shock to all assets, which comes on top of the normal behavior of an asset. We assume that the investor can invest in $n$ assets.

First, consider the set of states that apply to the return process. We assume that each asset $i$ 's basic return component can be in one regime $Q_{i}$ from a set of $K$ regimes. For the crisis component two regimes $Q_{c}$ are available: presence $\left(Q_{c}=1\right)$ and absence $\left(Q_{c}=0\right)$, and since the crisis is systemic the crisis regime applies to all assets. Consequently, the state that applies to the joint returns, $\tilde{Q}$, is completely defined by the combination of each asset's basic regime and the crisis regime ${ }^{6}$ :

$$
\tilde{Q} \equiv\left(Q_{1}, Q_{2}, \ldots, Q_{n}, Q_{c}\right)
$$

We use $Q$ to denote the combination of basic regimes, $Q \equiv\left(Q_{1}, Q_{2}, \ldots, Q_{n}\right)$. The sets $\mathbb{Q}$ and $\tilde{\mathbb{Q}}$ collect all possible state vectors $Q$ and $\tilde{Q}$, respectively. The actually prevailing state will never be known with certainty. Instead, each state prevails with a certain probability, inferred from the data.

The return vector can be split into a basic component and a crisis component. We assume that for each state $Q \in \mathbb{Q}$ the basic component $x$ is a normally distributed random vector, characterized by a state-specific mean $\mu_{Q}$ and variance matrix $\Omega_{Q}$. The marginal

\footnotetext{
${ }^{6}$ We use the expression state to refer to a combination of the basic regimes and the crisis regimes.
} 
distribution of asset $i$ 's basic component depends only on the regime $Q_{i}$ that applies. The crisis component consists of a shock, represented by a univariate random variable $x_{c}$, to which each asset has a specific sensitivity $\delta_{i}$. Following Das and Uppal (2004) and Liu et al. (2003) we assume that the shock has a normal distribution, with mean $\mu_{c}$ and variance $\omega_{c}$. Combining the two components gives the return vector:

$$
r=x+Q_{c} x_{c} \delta, \quad Q_{c} \in\{0,1\}
$$

where $\delta$ is the vector of sensitivities. Conditional on the state $\tilde{Q} \in \tilde{\mathbb{Q}}$, the return is normally distributed, being the sum of two (conditionally) normally distributed variables. Under the assumption that the shock and the basic component are independent, the mean vector $\mu_{\tilde{Q}}$ and variance matrix $\Omega_{\tilde{Q}}$ of the return can be written as:

$$
\begin{gathered}
\mu_{\tilde{Q}}=\mu_{Q}+Q_{c} \mu_{c} \delta, \\
\Omega_{\tilde{Q}}=\Omega_{Q}+Q_{c} \omega_{c} \delta \delta^{\prime}
\end{gathered}
$$

Because we want the shock to have the same direction for each asset, we require $\delta_{i} \geq 0$ for each $i$. Consequently, each variance and covariance term will increase if $Q_{c}=1 .^{7}$

The final element we add to the model are the transition probabilities that govern the Markov chains that the regime processes follow. We assume that the transition probabilities are constant over time, but we deviate from the two common approaches in the literature of either estimating each probability as a free parameter or assuming independence between the transition probabilities for the different assets. The first approach would lead to a very large number of unknown parameters ( $n$ assets than can each be in $K$ regimes and encounter a crisis lead to $2 K^{n} \cdot\left(2 K^{n}-1\right)$ parameters $)$, while the second approach implies the absence of volatility spill-over effects, being the tendency of high volatility in one asset's

\footnotetext{
${ }^{7}$ The correlation will rise if the relative increase in covariance exceeds the product of relative increase in volatilities. This condition will generally be satisfied for correlations not too close to 1 . In our model this change in correlation is completely due to the occurrence of a crisis. Consequently, using the terminology of Forbes and Rigobon (2002), our model implies interdependence of assets but not contagion.
} 
return to spread to other assets. ${ }^{8}$ Given the evidence in favor of volatility spill-over this implication is too restrictive. Therefore, we choose a different approach.

Let $\pi^{a b}$ denote the conditional probability of a switch to state $\tilde{Q}^{a}$, given that the current state is $\tilde{Q}^{b}$. First, we impose a structure based on the crisis regime.

- If a crisis occurs neither in the current state $\left(Q_{b}^{c}=0\right)$ nor in the destination state $\left(Q_{a}^{c}=0\right)$, we model $\pi^{a b}$ as the product of the marginal conditional probabilities $\pi_{i}\left(Q_{i}^{a} \mid \tilde{Q}^{b}\right)$ and the conditional probability that a crisis does not occur, given the current state $\tilde{Q}^{b}$. Here, $\pi_{i}^{a b}$ gives the probability that asset $i$ switches to regime $Q_{i}^{a}$, given that the current state is $\tilde{Q}^{b}$. The dependence on the state $\tilde{Q}^{b}$ instead of the asset-specific regime $Q_{i}^{b}$ introduces dependence across assets and enables the incorporation of volatility spill-over effects. We use a multinomial logistic model to model this dependence, which we discuss in the appendix. ${ }^{9}$

- If a crisis occurs in the destination state $\left(Q_{a}^{c}=1\right)$, but does not occur in the current state $\left(Q_{b}^{c}=0\right)$, we restrict the transitions such that the regime processes for the assets switch to the regime with the highest volatility. This restriction imposes that global stress triggers local stress.

- For the case that a crisis occurs both in the current and the destination state, we impose the same restriction as in the previous case. It prohibits illogical switches from high volatility regimes to lower volatility regimes, while a crisis remains present.

- If the assets currently encounter a crisis $\left(Q_{b}^{c}=1\right)$, which disappears in the destination state $\left(Q_{c}^{a}=0\right)$, the basic regime processes remain in the highest volatility regimes in the next period. After that, they can switch to other regimes. This restriction captures a gradual cooling down of assets after a crisis.

\footnotetext{
${ }^{8}$ Several authors have established volatility spill-over effects for different markets: Hamao et al. (1990) for the US, UK and Japan; Bekaert and Harvey (1997) and Ng (2000) for the US, Japan, and other Pacific-Basin markets; Edwards and Susmel (2001) for emerging markets in Asia and Latin America; Lee et al. (2004) for the US and Asian markets; and Baele (2005) for European countries.

${ }^{9}$ Bae et al. (2003) use a related model to investigate contagion.
} 
Finally, we assume that the crisis transition probabilities are independent of the assetspecific regimes. This leads to two parameters for the crisis transition probabilities: $\pi_{c}^{10}$, the probability that a crisis occurs in the destination state, but did not occur in the current state, and $\pi_{c}^{11}$, the probability that a crisis occurs in both the current state and the destination state. If we assume without loss of generality that the regimes are ordered in ascending order of volatility, we can represent our model as follows:

$$
\pi^{a b}= \begin{cases}\pi_{1}^{a b} \cdot \pi_{2}^{a b} \cdots \pi_{n}^{a b} \cdot\left(1-\pi_{c}^{10}\right) & \text { if } Q_{c}^{a}=0, Q_{c}^{b}=0 \\ \pi_{c}^{10} & \text { if } Q_{c}^{a}=1, Q_{c}^{b}=0, \forall i Q_{i}^{a}=K \\ \pi_{c}^{11} & \text { if } Q_{c}^{a}=1, Q_{c}^{b}=1, \forall i Q_{i}^{a}=K \\ 1-\pi_{c}^{11} & \text { if } Q_{c}^{a}=0, Q_{c}^{b}=1, \forall i Q_{i}^{a}=K \\ 0 & \text { otherwise }\end{cases}
$$

The crisis ignorant strategy imposes the restriction that transitions to $Q_{c}^{a}=1$ have zero probability. The consequences of this restriction are twofold. First, the crisis ignorant strategy will lead to different inferences and forecasts about the prevailing regime. Second, if the investor incorrectly follows an ignorant strategy and estimates the parameters of the process, the estimates for the parameters (both the distribution parameters and the transition matrix) are likely to be biased.

\subsection{The asset allocation problem}

The investor is risk averse and maximizes his utility over terminal wealth $W_{T}$. We assume he has a power utility function:

$$
U\left(W_{T}\right)=\frac{W_{T}^{1-\gamma}}{1-\gamma}, \quad \gamma>0, \gamma \neq 1
$$

where $\gamma$ is the investor's coefficient of relative risk aversion ${ }^{10}$. To focus on the effect of a systemic crisis on asset allocation, we do not allow intermediate consumption. As such, our

\footnotetext{
${ }^{10}$ For $\gamma=1$ the utility function is defined as $\log$ utility $U\left(W_{T}\right)=\ln W_{T}$.
} 
analysis is comparable to other studies such as Ang and Bekaert (2002), Liu et al. (2003) and Das and Uppal (2004). The investor can trade in continuous time. At each point in time $t$ he will choose to invest proportions of his wealth in the $n$ risky assets, collected in the vector $\phi_{t}$ and the remaining part $1-\phi_{t}^{\prime} \iota_{n}$ in the riskless asset $\left(\iota_{n}\right.$ being a vector of size $n$ with ones) in order to maximize expected utility:

$$
\max _{\left\{\phi_{t}, 0 \leq t \leq T\right\}} E_{0}\left[U\left(W_{T}\right)\right] .
$$

We assume that the investor has an initial endowment $W_{0}$. This assumption and a process for the asset prices enables us to derive the investor's self-financing constraint, which describes the dynamics of the wealth process. As we will describe below, we use a specific Itô process in continuous time that is consistent with the discrete time return process described in the previous section. For the moment, let the (multivariate) Itô process be given by:

$$
d r=\mu d t+\Lambda d Z
$$

where $\mu \equiv \mu(r, t)$ is the vector of instantaneous drift rates, which can depend on the return up to time $t$ and time itself, $\Lambda \equiv \Lambda(r, t)$ is a lower triangular $n \times n$ matrix that can also be a function of $r$ and $t$, and $d Z$ is a vector of $n$ independent Wiener processes. Consequently, the instantaneous variance rate $\Omega$ is given by $\Omega=\Lambda \Lambda^{\prime}$. The process for asset prices can be derived by applying Itô's lemma to the exponential relation between returns and prices:

$$
d S=\left(\mu+\frac{1}{2} \operatorname{diag}(\Omega)\right) S d t+\Lambda S d Z
$$

where $\operatorname{diag}(\Omega)$ denotes a column vector containing the diagonal elements of $\Omega$. The riskless asset pays the risk-free rate $r_{f}$. The self-financing condition reads:

$$
\frac{d W}{W}=r_{f} d t+\phi^{\prime} \alpha d t+\phi^{\prime} \Lambda d Z
$$

where $\alpha \equiv \mu+\frac{1}{2} \operatorname{diag}(\Omega)-r_{f} \iota_{n}{ }^{11}$.

\footnotetext{
${ }^{11}$ The expression can be interpreted as an excess, arithmetic mean return.
} 
The asset allocation problem constituted by Eq. (7) and (10) can be solved using standard stochastic control techniques ${ }^{12}$. We start with the indirect utility function:

$$
V(W, t)=\max _{\phi_{s}, t \leq s \leq T} E_{t}\left[U\left(W_{T}\right)\right]
$$

The Hamilton-Jacobi-Bellman equation takes the form:

$$
\max _{\phi}\left(\frac{\partial V}{\partial t}+\left(r_{f}+\alpha \phi^{\prime}\right) W \frac{\partial V}{\partial W}+\frac{1}{2} \phi^{\prime} \Omega \phi W^{2} \frac{\partial^{2} V}{\partial W^{2}}\right)=0
$$

We conjecture (and verify) that the indirect utility function is of the form:

$$
V(W, t)=C(t) \frac{W^{1-\gamma}}{1-\gamma}, \quad \gamma \neq 1
$$

Based on this functional form ${ }^{13}$, we derive expressions for the derivatives in Eq. (12) and substitute them. We can now differentiate Eq. (12) with respect to $\phi$, and solve the firstorder condition to find the optimal portfolio weights for the risky assets $\phi^{*}$ :

$$
\phi^{*}=\gamma^{-1} \Omega^{-1} \alpha=\gamma^{-1} \Omega^{-1}\left(\mu+\frac{1}{2} \operatorname{diag}(\Omega)-r_{f} \iota_{n}\right) .
$$

Though this expression has the same structure as the solution to a standard mean-variance optimization problem, both $\mu$ and $\Omega$ will be shown to depend on time and the observed returns, making the weights depending on them as well. This expression also applies to the log-utility investor.

\subsection{The Itô process for returns}

Brigo (2002) describes a way to derive continuous time processes whose corresponding density at a certain point in time is a mixture of densities from the same family ${ }^{14}$. This approach has two advantages. First, it facilitates the use of the powerful techniques developed for continuous time finance. Second, the continuous time processes that result from

\footnotetext{
${ }^{12}$ See for example Léonard and Van Long (1992).

${ }^{13}$ For $\gamma=1$ we use $V=\ln [C(t) W]$.

${ }^{14}$ Applications of this technique can be found in Alexander and Narayanan (2001), Alexander and Scourse (2004) and Brigo and Mercurio (2002).
} 
his approach include the different regimes directly in their parameters without introducing extra state variables for the different regimes. Consequently, the regimes are implicitly present in the portfolio optimization (i.e. in the parameters of the Itô process), and do not lead to regime-specific Itô processes.

Since the distribution of $r_{\tau+1}$ conditional on its filtration is a mixture of normal distributions (see Hamilton, 1994, Ch. 22), we can apply a multivariate extension of Theorem 2 in Brigo (2002). Consequently, the Itô process in Eq. (8) starting at $t_{0}=\tau$ with $r_{t_{0}}=0$ has a mixture density at time $\tau+1$ which corresponds with the mixture model implied by the regime switching model, if the instantaneous drift rate $\mu(r, t)$ and instantaneous variance rate $\Omega(r, t)$ are given by:

$$
\begin{aligned}
\mu(r, t) & =\sum_{\tilde{Q} \in \tilde{\mathbb{Q}}} \pi(\tilde{Q}, r, t) \mu_{\tilde{Q}} \\
\Omega(r, t) & =\sum_{\tilde{Q} \in \tilde{\mathbb{Q}}} \pi(\tilde{Q}, r, t) \Omega_{\tilde{Q}}
\end{aligned}
$$

with

$$
\pi(\tilde{Q}, r, t)=\frac{\xi_{\tau+1 \mid \tau}(\tilde{Q}) \cdot f\left(r_{t} ; \mu_{\tilde{Q}}(t-\tau), \Omega_{\tilde{Q}}(t-\tau)\right)}{\sum_{\hat{Q} \in \tilde{\mathbb{Q}}} \xi_{\tau+1 \mid \tau}(\hat{Q}) \cdot f\left(r_{t} ; \mu_{\hat{Q}}(t-\tau), \Omega_{\hat{Q}}(t-\tau)\right)},
$$

where $\tau<t \leq \tau+1$, and $\xi_{\tau+1 \mid \tau}(\tilde{Q})=\operatorname{Pr}\left(\tilde{Q}_{\tau+1} \mid \mathcal{F}_{\tau}\right)$ gives the forecast probability that state $\tilde{Q}$ is prevailing at time $\tau+1 .^{15} \Lambda(r, t)$ can then be found by applying a Cholesky decomposition to $\Omega(r, t)$. For $t=\tau$, Eq. (17) reduces to $\pi(\tilde{Q}, 0, \tau)=\xi_{\tau+1 \mid \tau}(\tilde{Q})$.

The drift and variance rate constructed by Eq. (15), (16) and (17) have an appealing interpretation. First, notice that the drift and variance are a probability weighted average of the mean and variance parameters for the different states. These probabilities have a clear interpretation as inference probabilities, which are commonly used in regime switching models (see Hamilton, 1994, eq. 22.4.5). Furthermore, Eq. (17) is a Bayesian update rule, with $\xi_{\tau+1 \mid \tau}(\tilde{Q})=\operatorname{Pr}\left(Q_{\tau+1} \mid \mathcal{F}_{\tau}\right)$ as prior probability for the prevailing regime and $\pi(\tilde{Q}, r, t)=$ $\operatorname{Pr}\left(Q_{\tau+1} \mid r_{t}, \mathcal{F}_{\tau}\right)$ as its posterior probability. Consequently, the weight $\pi(\tilde{Q}, r, t)$ gives the

\footnotetext{
${ }^{15}$ We follow the notation in Hamilton (1994).
} 
probability that state $\tilde{Q}$ is prevailing from $\tau$ until $\tau+1$, inferred from the realization of $r$ from $\tau$ till $t \leq \tau+1$. If the probability that state $\tilde{Q}$ is prevailing rises, the weight with which its parameters constitute the instantaneous drift and variance rate increases linearly with it. In the limiting case that state $\tilde{Q}$ is prevailing with certainty, the return at time $t$ will be normally distributed with parameters $\mu_{\tilde{Q}}(t-\tau)$ and $\Omega_{\tilde{Q}}(t-\tau)$.

\subsection{Comparing portfolios}

Though the expression for the optimal portfolio Eq. (14) is the same for both the crisis conscious and the crisis ignorant strategy, the resulting portfolios ( $\phi^{c}$ and $\phi^{i}$ respectively) will differ because of differences in $\mu_{\tilde{Q}}, \Omega_{\tilde{Q}}$ and $\pi(\tilde{Q}, r, t)$. In this subsection we discuss how we will determine the economic importance of the portfolio differences and how we can explain them.

To assess the economic impact of the differences in portfolios we calculate the certainty equivalent return needed to compensate the investor for using the crisis ignorant strategy, when he should have used the crisis conscious one. Since the first does not take a crisis into account, the resulting portfolio will be suboptimal and yield lower utility. The certainty equivalent return shows by how much the initial wealth of the investor should be raised to compensate him for this utility loss and hence the cost of ignoring a crisis. We use the value function Eq. (11) given both portfolios ${ }^{16}$ to define the certainty equivalent return $\bar{r}$ :

$$
V\left(e^{\bar{r}} W_{t}, t ; \phi^{i}\right)=V\left(W_{t}, t ; \phi^{c}\right)
$$

Using the functional form in Eq. (13), we find after some rearrangements that

$$
\bar{r}=\frac{1}{1-\gamma}\left(\ln C\left(t ; \phi^{c}\right)-\ln C\left(t ; \phi^{i}\right)\right),
$$

which is independent of wealth ${ }^{17}$. To identify $C(t)$, consider the Hamiltonian Eq. (12) at the presumed optimal solution $\phi^{*}$, with derivatives based on Eq. (13). This equation

\footnotetext{
${ }^{16}$ We adopt the notation introduced by Das and Uppal (2004), and include the portfolio that is used to calculate the value function as a parameter.

${ }^{17}$ This return can be interpreted as a log return, while other papers such as Ang and Bekaert (2002), Liu et al. (2003) and Das and Uppal (2004) define the certainty equivalent return as a discrete return.
} 
implies an ordinary differential equation for $C(t)$ :

$$
d C=-(1-\gamma)\left[r_{f}+\phi^{* \prime} \alpha-\frac{1}{2} \gamma \phi^{* \prime} \Omega \phi^{*}\right] C(t)
$$

This differential equation can be solved straightforwardly, yielding:

$$
C\left(t ; \phi^{*}\right)=\eta \exp \left[-(1-\gamma)\left(r_{f}+h\left(\phi^{*}\right)\right) t\right]
$$

with integration constant $\eta$ and $h\left(\phi^{*}\right) \equiv \phi^{* \prime} \alpha-\frac{1}{2} \gamma \phi^{* \prime} \Omega \phi^{*}$. Finally, we can solve for $\eta$ by using the boundary condition $V\left(W, T ; \phi^{*}\right)=U\left(W_{T}\right)$, which gives $\eta=\exp \left[(1-\gamma)\left(r_{f}+\right.\right.$ $\left.\left.h\left(\phi^{*}\right)\right) T\right]$. Substituting this for $\eta$ produces the final result

$$
C\left(t ; \phi^{*}\right)=\exp \left[(1-\gamma)\left(r_{f}+h\left(\phi^{*}\right)\right)(T-t)\right]
$$

We can combine the more general expressions Eq. (19) and Eq. (20) to find an expression for the certainty equivalent return that is specific for the type of models in this paper ${ }^{18}$ :

$$
\bar{r}=\left[h\left(\phi^{c}\right)-h\left(\phi^{i}\right)\right](T-t) .
$$

This expression is interesting in several ways. First, we observe that it only depends on the coefficient of risk aversion $\gamma$ via the function $h$ and the portfolio $\phi^{*}$. It is easy to show that $h\left(\gamma^{-1} \phi^{*}\right)=\gamma^{-1} h\left(\phi^{*}\right)$. Consequently, the certainty equivalent return needed to compensate a power utility investor can be derived from the certainty equivalent return for the log utility investor. Second, the certainty equivalent return is a linear function of the investor's horizon $T$.

The portfolio differences can stem from differences in the estimates for the basic regimes, the estimation effect, and the absence of crisis regimes, the crisis effect. An analysis of these differences provides insights into the importance of both sources. Suppose that the differences in parameter estimates explain just a small part of the changes in the optimal allocations. In that case, the crisis regime is the main driver of the portfolio adjustments. Alternatively, if the differences in parameter estimates explain most of the changes in

\footnotetext{
${ }^{18}$ For the $\log$ utility investor we have $V=\ln [C(t) W], \bar{r}=\ln C\left(t ; \phi^{c}\right)-\ln C\left(t ; \phi^{i}\right)$ and $C\left(t ; \phi^{*}\right)=$ $\exp \left[h\left(\phi^{*}\right)(T-t)\right]$, and arrive again at Eq. (21).
} 
optimal portfolios, the influence of the crisis itself is limited. The observations that belong most likely to the crisis regime cause outlier problems in the crisis ignorant case.

In order to disentangle the differences between the optimal allocations produced by the crisis conscious and ignorant strategies we introduce a myopic strategy. This strategy uses the same estimates as the crisis conscious strategy, but excludes a crisis regime in the forecasts it makes. Instead of forecasts for state vectors in the complete state space $\xi_{\tau+1 \mid \tau}(\tilde{Q})$, only forecasts for the basic states: $\xi_{\tau+1 \mid \tau}^{m}(Q)$ are constructed. Their mathematical relation is:

$$
\xi_{\tau+1 \mid \tau}^{m}(Q)=\xi_{\tau+1 \mid \tau}\left(Q, Q^{c}=0\right)+\xi_{\tau+1 \mid \tau}\left(Q, Q^{c}=1\right), \quad Q \in \mathbb{Q}
$$

The myopic strategy produces an allocation $\phi^{m}$. We interpret the differences between the myopic and the crisis ignorant strategy $\phi^{e} \equiv \phi^{m}-\phi^{i}$ as the estimation effect, and the differences between the crisis conscious and myopic strategy as the crisis effect, $\phi^{s} \equiv$ $\phi^{c}-\phi^{m}$.

We can determine the economic importance of both effects in a similar way as we determine the impact of the overall differences in Eq. (21). To this end we calculate $h\left(\phi^{m}\right)$, and derive the economic importance of the estimation effect as $\bar{r}^{e}=\left[h\left(\phi^{m}\right)-h\left(\phi^{i}\right)\right](T-t)$ and the importance of the crisis effect as $\bar{r}^{s}=\left[h\left(\phi^{c}\right)-h\left(\phi^{m}\right)\right](T-t)$.

\section{Design of the analysis}

Central in our analysis of the impact of systemic crises is a US investor who wants to diversify his portfolio internationally. He can invest worldwide and does not only consider developed markets, but also emerging markets, which can extend diversification opportunities $^{19}$. The developed markets he considers are the US, European, Japanese and Hong Kong market; among the emerging markets he considers Thailand, Korea and Brazil, which

\footnotetext{
${ }^{19}$ Early studies (see e.g. Harvey, 1995) find significant diversification opportunities, but more recent studies show these may be less when transaction costs and investment constraints are taken into account (see Bekaert and Harvey, 2003, for a discussion).
} 
are among the largest. We represent each market by an index. For each index we construct a return series, on which the models for the crisis conscious and the crisis ignorant strategies are estimated. We assume that for each country 2 regimes can be distinguished. The estimation results are used to construct allocations. Based on the differences between the allocations resulting from the crisis conscious strategy and the crisis ignorant strategy we determine the impact of systemic crises. In the remainder of this section we discuss the elements of the analysis in more detail.

We base the analysis on monthly returns, mainly because monthly data are available with the longest history. A systemic crises is a rare event, necessitating a relatively long history to get an accurate estimate of the probability of a systemic crisis. A longer horizon also improves the estimate for the mean returns in the different regimes. Each developed market is approximated by its corresponding gross return index from Morgan Stanley Capital International (MSCI). For the emerging markets we use the gross return indexes provided by Standard \& Poors / International Finance Corporation (IFC), both provided by DataStream. We use the start of the IFC indexes, December 31, 1975 as a starting point for our analysis and collect the index values in dollars till December 31, 2004, resulting in 348 returns. We construct excess returns by subtracting the 1-month T-bill return from Ibbotson Associates, Inc. ${ }^{20}$

A summary of the data is provided in Table 1 . We observe the familiar picture of small, positive means, non-zero skewness and fat tails. Generally, the minimum exceeds the maximum in absolute value. The correlation matrix shows low levels of correlation, particularly for the emerging markets, implying the presence of diversification possibilities. However, Hong Kong, Thailand, Korea and Brazil may be less attractive due to their relatively high levels of volatility.

\section{[Table 1 about here.]}

The regime switching models we propose in Section 2 belong to the standard regime

\footnotetext{
${ }^{20}$ We use the series available on the website of Kenneth French, http://mba.tuck.dartmouth.edu/pages/faculty/ken.french/data_library.html.
} 
switching models as discussed in Hamilton (1994). We use the expectation maximization algorithm (see Dempster et al., 1977; Hamilton, 1990) to estimate the parameters in the models. Central in this algorithm is a filtering technique to determine the state probabilities at each point in time. If the improvement in the likelihood function falls below a specified limit, the algorithm stops. To ensure that the estimate covariance matrix is positive definite, we assume that the correlation matrix is independent of the basic state vectors.

The expression for the optimal portfolio in Eq. (14) defines an asset allocation strategy in continuous time. This means that we can derive the evolution of portfolios over time for a given price path. We construct paths of portfolios based on daily prices. The data we use are the daily prices of the mentioned gross return indexes in dollar terms, also gathered from DataStream. To keep the daily and monthly data sets consistent, we use the 1-month T-bill rate that was prevailing at the beginning of the month to compute the daily excess returns.

The portfolio at a given day of the month reflects two sources of information: a prior probability based on the information at the beginning of the month, and the information present in the returns observed until that day. The second source of information is used to update the prior probability to a posterior probability as in Eq. (17). We interpret the prior probability as the outcome of an investor's thorough analysis of the likelihood of a state. Because of its thoroughness such an analysis is conducted at a limited frequency, i.e. once per month. We represent the outcomes of the analysis by a Markov chain. The prior probability can be regarded as an informative prior, because it is based on all available information at the moment it is determined. We will also consider the allocation that results if the investor does not use the observed stock price path to determine the prior probabilities. Instead, the investor uses unconditional probabilities for each regime, which are only based on the transition matrices. The results from this analysis can serve as a benchmark and can be compared to the results in Das and Uppal (2004). 


\section{Estimation results}

In this section we present and discuss the results from estimating the models for the returns in the two strategies. We split the discussion in two: first we consider the estimates for the distributions under the different regimes; next we turn to the parameter estimates for the transition probabilities of the Markov chains.

Table 2 presents the estimates for the parameters of the marginal normal distributions. The main difference between the crisis ignorant and crisis conscious strategy is the presence of the crisis regime in the latter one. The crisis regime contains a shock with an estimated mean of $-0.63 \%$ and a volatility of 1.54 . The shock has been normalized such that the US has a sensitivity of 1 . The other countries (except Europe) are more sensitive to the shock, in particular the emerging countries Korea and Thailand which are more than 10 times as sensitive as the US. The considerable difference in $\log$ likelihood valuess ${ }^{21}$ of 19.0 , provides evidence in favor of the addition of a crisis regime. However standard statistical tests cannot be used, because several parameters are not identified under the null hypothesis. ${ }^{22}$

[Table 2 about here.]

We observe that for both models, the two basic regimes for each asset can be distinguished by their volatility levels. This finding has been previously reported by Ramchand and Susmel (1998), Ang and Bekaert (2002) and Graflund and Nilsson (2003). In the remainder we will therefore use the terms low volatility regime and high volatility regime to distinguish between the regimes.

Based on the estimates for the shock and the basic high volatility regimes, we can derive the means and volatilities in the crisis regime. As expected, the crisis regime exhibits a

\footnotetext{
${ }^{21}$ The $\log$ likelihood values for the models without and with a crisis equal -8029.5 and -8010.5 , respectively.

${ }^{22}$ Hansen (1992) proposes a method to formally test whether the addition of a regime is a significant improvement. In this method, the likelihood function is maximized over different combinations of fixed values for the restricted and nuisance parameters. The number of combinations grows exponentially in the number of parameters, which makes the method less attractive to test the significance of the crisis regime.
} 
sharp drop in expected returns and an increase in volatilities. Because of their large sensitivity to a crisis, these effects are most pronounced for emerging markets, which may also offer an explanation for the fat tails reported by Susmel (2001). Table 3 shows that the correlations in the crisis regime are also higher, as has been reported before by Ang and Chen (2002) and Forbes and Rigobon (2002). It is obvious that the risk-return trade-off for each asset deteriorates, while the correlation matrix shows that diversification possibilities also become less. Consequently, risky assets become less attractive on a global scale. However, the correlation between the emerging markets on the one hand and the US and Europe on the other hand remain low. The exact consequences become clear in the next section.

The addition of a crisis regime has important effects on the other estimates as well. The risk within each regime becomes less, as most volatility estimates decrease, particularly those in the high volatility regime. Moreover, the means in the high volatility regimes increase considerably, indicating that the few crisis observations differ substantially from normal high volatility periods.

[Table 3 about here.]

Table 4 presents the estimates for the parameters of the logistic functions that we use to construct the regime transition probabilities (see the Appendix for more details). In total, we have $2 \cdot 7^{2}=98$ parameters from which we construct the $128 \times 128\left(=2^{7}\right)$ basic transition matrix. The diagonal elements give the estimates that correspond with no regime switch for a country, given that the other countries are currently in their low volatility regimes. The off-diagonal elements give the volatility spill-over estimates, which are restricted to be negative (positive) for switches from the low (high) volatility regimes. Because of these restrictions, volatility spill-over effects increase the probability that countries are in their high volatility regimes. As an example, consider the Hong Kong market. The probability that the Hong Kong market remains in its low volatility regime, given that the other markets are also in their low volatility regimes equals $e^{3.75} /\left(1+e^{3.75}\right)=0.98$. However, we find volatility spill-over from the US to Hong Kong: if the US is in its high 
volatility remain, the probability that Hong Kong switches from low to high volatility is $e^{3.75-0.48} /\left(1+e^{3.75-0.48}\right)=0.96$.

[Table 4 about here.]

We draw several conclusions from the estimates in Table 4. First of all, each regimes is in itself strongly persistent, as indicated by high values for the positive diagonal elements (exceptions are the high volatility regimes for Japan and Korea). Second, volatility spillover effects mainly affect the probability of a switch from the low volatility to the high volatility regimes; the probability that a country remains in its high volatility regime, given that other countries are also in their high volatility regimes, is less affected. Third, volatility spill-over effects are mainly present among the developed markets, and from emerging markets to developed markets. Other studies finds volatility spill-over effects from the US and Japan to other Asian markets, such as Hong Kong, Thailand and Korea (see Bekaert and Harvey, 1997; Ng, 2000; Lee et al., 2004), but this may be due to differences in the applied methods (GARCH-models versus regime switching models; daily vs. monthly data).

Finally, we consider the probability estimates for a systemic crisis. A crisis has a probability of 0.0031 to occur, given that currently no crisis occurs. However, if a crisis occurs, it is highly persistent, as indicated by the probability of 0.93 of remaining in the crisis regime. Unconditionally, if no prior information on the prevailing regimes is available, the crisis regime occurs with a probability of 0.045. Das and Uppal (2004) estimate a probability on a systemic jump of 0.0501 for the developed markets and of 0.0138 for the US with emerging markets, which is comparable to the unconditional probability we find. However, in their model, a systemic jump at this instant does not affect the probability of a jump in the next instant, which remains relatively low as a consequence. This illustrates the main difference between their model and the model we propose. 


\section{Portfolio construction}

Based on the estimates of the previous section we construct optimal portfolios for the crisis conscious and crisis ignorant strategies. The portfolios vary over time and depend on the filtration of the return processes, limiting the relevancy of an analysis of static portfolios. Instead, we concentrate on two situations. First, we consider the influence of a crisis when the investor uses uninformative forecast probabilities for the likelihood of the different regimes, or in other words has no prior knowledge on the state of the economy. In the second situation we analyze the effects of a crisis when the investor uses informative forecasts in a period in which the probability that a crisis was actually prevailing was high, being the second half of 1997, when the Asian crisis took place. We concentrate on October 1997, the month in which the Hong Kong market crashed. The second situation is the more interesting one, since we can observe how both strategies perform in a real-life situation. The first situation will be useful as a benchmark and enables a comparison with the results of Das and Uppal (2004) and Liu et al. (2003).

For both cases we conduct an analysis consisting of the same steps. We present and motivate the steps here, together with their main outcomes. We start by deriving and comparing the optimal allocations for the log utility investor. Though the assumption of $\log$ utility is unrealistic due to its low degree of risk aversion, the log utility portfolio is popular in asset allocation studies. The optimal portfolio for a power utility investor is the $\log$ utility portfolio scaled by the inverse of his coefficient of relative risk aversion and an investment in the riskless asset to meet the budget constraint. The considerable differences between the crisis conscious and crisis ignorant strategies that we find indicate that the crisis conscious strategy invests less in risky assets. An inspection of only the risky part shows that the crisis conscious strategy shifts investment to countries less prone to a crisis.

Next, we determine the economic importance of the differences between the two strategies. We calculate the certainty equivalent return that the investor requires as a compensation for adopting the crisis ignorant strategy, when the crisis conscious strategy is appropriate. For the uninformative case, the costs of ignoring the possibility of a systemic 
crisis are limited, but large enough not to neglect them, particularly for longer horizons. In the second situation, when a crisis takes place with almost certainty, the certainty equivalent return rises substantially, also for more risk averse investors.

We conclude the analysis by investigating what can explain the differences between the crisis conscious and crisis ignorant portfolios: the differences in the parameters estimates for the basic component, or the hedging demand due to the possibility of a crisis. To accomplish this we use the myopic strategy introduced in Section 2.4. This strategy uses the same estimates for the basic part as the crisis conscious model, but excludes the crisis regime from the forecasts it makes. Consequently, the differences between the portfolios produced by the crisis ignorant and the myopic strategies are due to different parameter estimates for the basic component. On the other hand, the differences between the myopic strategy and the crisis conscious strategy stem solely from the crisis regime. These latter differences have the clear interpretation of a hedging demand. We find that the investor hedges against a crisis by taking a long position in the US, Europe, and the riskless asset and a short position in the stock markets of the other countries.

In the next two subsections we report the actual analysis in more detail. In the last subsection we discuss some robustness checks.

\subsection{Static analysis}

In Table 5 we present the portfolios that a log utility investor would construct, if he has no information on the price path of the assets so far. Most importantly, the crisis conscious strategy results in a less aggressive allocation than the crisis ignorant strategy. Overall, the position is less leveraged: the investor lends 3.79 times his initial wealth opposed to 4.71 under the crisis ignorant strategy. Das and Uppal (2004) report similar, though less pronounced results. Leverage is large because we report the log utility portfolio. An investor with coefficient of relative risk aversion equal to 5 would invest $4 \%$ in the risk free asset, adopting the crisis conscious, or lend $14 \%$ of his wealth, if he adopts the crisis ignorant strategy. The risky asset portfolio itself does not change much. 
[Table 5 about here.]

It is costly to ignore the possibility of a crisis. A log-utility investor who incorrectly adopts the crisis ignorant strategy requires a certainty equivalent return of $0.09 \%$ per month (or $1.13 \%$ per year) as compensation. For more risk averse investors, the required compensation becomes less, as the certainty equivalent return should be divided by their coefficient of relative risk aversion. A comparison of this result with findings of Das and Uppal (2004) highlights the importance of persistence. Das and Uppal (2004) report that an investor with coefficient of relative risk aversion of 3 and a horizon of 1 year requires a return of $0.1 \%$ as compensation for incorrectly ignoring the systemic jumps in their model. A similar investor in our approach would require a return of $0.38 \%$ for incorrectly following the crisis ignorant strategy. Since both systemic events have a comparable probability of occurrence, we conclude that persistence increases the importance of systemic crises. Das and Uppal also show that the certainty equivalent return is an increasing and convex function of the probability of a systemic crisis (see Das and Uppal, 2003, Section 5.2.5, Appendix A.2 and Figure 4), but the degree of persistence they consider is fairly low.

Overall, the decomposition of the differences shows that the estimation effect causes a more prudent allocation: leverage is decreased by 0.40 . However, within the risky asset part of the portfolio, investments shift from the US and Europe to Asia. A comparison of the estimates for the high volatility regimes in the crisis conscious model with those in the crisis ignorant model, shows that particularly the high volatility regimes for the Asian markets become more attractive. Of course, this implies that the crisis regimes entails substantial risk for investments in Asian equity. The crisis effect cause large divestments in Asia, which are partly directed towards the US and European markets and partly to the riskless asset. In the uninformative case, the estimation effect and crisis effect cancel out more or less for the Asian markets, but for the developed market the estimation effect dominates. Also in an economic sense the crisis effect is the more important. A log-utility investor requires a compensation of $0.31 \%$ per month for ignoring the crisis effect. If he also ignores the estimation effect, the required compensation reduces to $0.1 \%$ per month. 
Overall, we conclude that the implications of the possibility of a systemic crises are already visible in an uninformative, static setting. Including a crisis regime in the model for asset returns leads to improved estimates for the basic regime, and boosts investments in emerging markets, but the probability of large negative returns curbs it. Though the estimation effect dominates, the combined effects shift investments to the riskless asset, indicating that incorporating a crisis leads to prudence. Ignoring this prudence can cost up to $1.13 \%$ per year.

\subsection{October 1997: the Asian crisis}

After studying the effects of a systemic crisis when no prior information is used, we now turn to an informative setting. We investigate the implications of the strategies for asset allocation in October 1997, the month during which the Hong Kong market crashed. We take the estimates presented in the previous sections as given. The inference probabilities that the investor uses are constructed by applying the filtering technique described in Hamilton (1994) on the data set up to September 1997. This setup enables us to observe how the dive of the Hong Kong market influenced the inference probabilities and consequently the asset allocation. The calculation of certainty equivalent returns and decompositions can help us to understand the changes in optimal asset allocations over time, caused by the continuous updating of the inference probabilities.

The Asian crisis hit financial markets during the second half of 1997. ${ }^{23}$ In August 1997 the Thai market crashed. Only after the crash of the Hong Kong market, the shocks in Asia were considered as a global crisis. An inspection of the inference probabilities of our model produces a similar picture. By the end of August and September the inferred probability for the crisis regime did not exceed 0.05 , but by the end of October it had risen to almost 1. The smoothed inference probabilities resulting from our model confirm the view that the sharp drop in the Thai market could be seen as an overture to the Asian crisis. After

\footnotetext{
${ }^{23}$ See Kamin (1999) for a broad discussion of the symptoms of the Asian crisis. Kaminsky and Schmukler (1999) investigate the causes of daily market fluctuations during the Asian crisis.
} 
August and September, the smoothed inference probability of the crisis regime was above 0.80, and from October onwards it remained close to 1.

Figure 1(a) plots the cumulative excess returns for the different countries. The cumulative returns in the Asian markets are already negative during the beginning of the month, but the US, Europe and Brazil realize small, positive returns. However, after October 17, 1997 (the 13th trading day of that month) the Hong Kong market starts to dive: from $-9.5 \%$ to $-50 \%$ in 7 days. The Thai and Korean market move in lock step, but the other markets also suffer large price drops, in particular the Brazilian market. At the end of October 20, a Monday, the inference probability for the crisis regime in the crisis conscious model climbs to 0.71 and remains high for the rest of the month. So the conscious strategy deems the crisis regime the most likely one for the second half of the month.

[Figure 1 about here.]

To see what the investor would infer had he not taken a crisis into account, we plot the inferences for the crisis ignorant model in Figure 1(c). In the first half of the month, it is inferred that the US and the Thai market, probably accompanied by the Hong Kong market, are in their high volatility regimes. After the sharp decline in the Hong Kong market it is inferred that in all markets the high volatility regime is prevailing, though some doubt exist regarding Japan and Brazil.

The allocations to which the crisis conscious and crisis ignorant strategies lead during the month are plotted in Figure 2. Adopting the crisis conscious strategy leads to less risky allocations. First of all, when applying the crisis conscious strategy, an investor uses less leverage as can be concluded from Figure 2(h). Both strategies start with approximately the same degree of leverage, but as October goes by and the probability of a crisis increases, leverage decreases faster in the crisis conscious strategy. By the end of the month the crisis conscious strategy has a long position in the risk free asset, while the crisis ignorant portfolio is still leveraged. It is particularly interesting to see that following the crisis conscious strategy leads to a sharp decrease in leverage already before the dive of the Hong Kong market. 
[Figure 2 about here.]

[Figure 3 about here.]

In the crisis conscious strategy, foreign markets quickly become less attractive as the probability of a crisis rises. For four of them (Japan, Hong-Kong, Thailand and Korea), the conscious strategy even advises short positions. When applying the crisis ignorant strategy, the investor decreases his exposure to some of these markets (Japan, Hong Kong), but he increases his exposure to Hong Kong and Korea by the end of the month and maintains long positions in these markets throughout most of the month. Again it is reassuring to see that the investor adopting the crisis conscious strategy withdraws quickly from the Hong Kong market, when the probability of a crisis rises. When adopting the crisis ignorant strategy, the Hong Kong market remains much longer attractive.

Based on this analysis, we conclude that the differences between the two strategies as revealed in Figure 2 are pronounced. Though interesting on themselves, the evolution of the certainty equivalent return presented in Figure 3 clearly demonstrates that the economic importance of these differences is also very substantial. For the complete month, so also before the dive of the Hong Kong market, the certainty equivalent return well exceeds the $0.09 \%$ per month that we found in the uninformative case, as it remains above $0.3 \%$ per month on each day. Moreover, it rises dramatically (to at most 4.0\%) after the crash of the Hong Kong market. Of course, these returns are lower for more risk averse investors, but we stress that these percentages correspond with a 1-month horizon.

[Figure 4 about here.]

The results also indicate that diversification opportunities deteriorate rapidly if the inference probability of a crisis increases. Already before the crisis hits, leverage decreases, investments are reduced and in some countries short position are taken. These findings can be seen as an addition to the results in Ang and Bekaert (2002), who conclude that diversification opportunities do not disappear when the bearish regime in their model is prevailing. Since the crisis regime in our model consists of the bear regime of each country 
and a shock (with a negative mean) on top of that, conditions are much worse in the crisis regime, and consequently we do observe such a deterioration.

We conclude the analysis by considering the estimation and crisis effects over October 1997, which are also plotted in Figure 2. From the crisis effect we conclude that also during a crisis, the US and European market and the riskless asset can be used to hedge against a crisis at the expense of investments in the other countries. We observe a positive demand for the US and European asset, and a strong and increasing positive demand for the riskless asset. Positions in other markets are more and more reduced, particularly in the emerging markets Korea and Thailand, which are most prone to a crisis. The estimation effect presents a less clear picture. In the uninformative case, the estimation effect causes investments to shift from the riskless asset to the risky assets. Now we observe a preference for Japan, Korea and Thailand. Within the risky asset part we observe a tendency to more aggressive allocations, but leverage is not increased much. The certainty equivalent returns associated with missing the crisis effect are also considerable, being always positive and rising rapidly. Of course, missing the crisis effect becomes extremely expensive after a crisis has occurred (with a maximum at 10\%). The estimation effect does not always harm the investor's utility. Finally, the estimation effect influences utility less (in absolute sense) than the crisis effect.

The portfolio differences and the corresponding certainty equivalent returns lead to several important conclusions. First, the differences and their importance become rapidly larger when the inference probability of a crisis increases. Second, an inference probability of a crisis of around 0.10 already leads to portfolio differences that are much larger than in the uninformative case (in that case the probability of a crisis equals 0.05) and much more costly to ignore. Third, an investor that adopts the crisis conscious strategy takes precautions well before the inference probability reaches high levels (exceeding 0.5). Finally, the occurrence of a crisis rapidly diminishes diversification opportunities. 


\subsection{Robustness checks}

In order to gauge the strength of our results, we subject them to several robustness checks. We start by repeating our analysis of the allocations during October 1997 for four different months during the Asian crisis: August, September, November and December. We continue by investigating the effects of short selling constraints on the different allocations. Next, we determine the portfolio turnover for the different strategies and use it to discuss the possible impact of transaction costs. In each following subsection, we discuss each robustness check briefly $^{24}$.

\subsubsection{Other months during the Asian crisis}

The Asian crisis was perceived as a global crisis after the collapse of the Hong Kong market and the following by other markets in October 1997. The crisis actually built up during August and September, but it was not perceived as a systemic crisis then. After October, the crisis was perceived to take place with almost certainty. This makes August, September, November and December interesting months to study as well.

In August the Thai market crashed, but it was not followed by other markets as much as the Hong Kong crash in October. In September the Thai market showed sharp fluctuations and the Korean market decreased considerably (at most -14\%). In November all Asian markets declined steadily. December showed again large declines for the emerging markets (in particular Korea and Thailand), though the other markets seemed to stabilize. Inference probabilities for a systemic crisis are low in August and September and high in November and December.

We perform the analysis discussed in section 5.2 for these months and find large similarities, which supports our conclusions based on October. In all months the crisis conscious strategy advises a smaller exposure to emerging markets. In August and September, it advises a higher exposure to the developed markets while in November and December, leverage is decreased. Because the inference probability for a crisis is large throughout

\footnotetext{
${ }^{24}$ The complete results are available from the authors.
} 
November and December, the certainty equivalent return to compensate for the crisis ignorant strategy is also large in those months (well above $5.0 \%$ for a log-utility investor with a 1 month horizon). In August and September, the inference probability for a crisis is low, but we still observe certainty equivalent returns that exceed the $0.09 \%$ that resulted from the uninformative case.

\subsubsection{Short sales constraints}

Large short positions as in Figure 2 may not be feasible. Therefore, we construct optimal allocations for both strategies for an investor facing short sales constraints. In the appendix we derive the optimal portfolio under the restriction that the portfolio weights for the risky assets are nonnegative. ${ }^{25}$ We use that result to determine the optimal allocation for both the uninformative case and the informative case of October 1997.

In the uninformative case, the consequences of short sales constraints are limited. Both strategies do not invest in Japan. The investments in the other countries are slightly reduced, but we mainly observe an increase in leverage of both portfolios. Because the portfolio adjustments are similar for both strategies, the decomposition in the estimation and the crisis effect, and the certainty equivalent return needed to compensate for the crisis ignorant strategy remain largely unaffected.

The analysis of October 1997 yields more interesting insights. First of all, the investor who uses the crisis conscious strategy leaves all markets, if a crisis occurs. In the appendix, we show that assets for which $\alpha \equiv \mu_{i}+\frac{1}{2} \omega_{i}-r_{f}$ is negative and the covariance with other assets is positive are not invested in. Based on the parameters reported in Tables 2 and 3 we conclude these conditions are satisfied. During October 1997, a crisis does not occur with certainty, but its inferred probability is large enough.

Figure 4 shows the allocations for the trading days in October 1997. Imposing short sales constraints results in less volatile and less aggressive allocations for both strategies. The conscious strategy stays out of the Japanese, Hong Kong and Korean market during

\footnotetext{
${ }^{25}$ For a more general treatment of optimal portfolio selection for investors with CRRA utility facing short sales constraints, see Teplá (2000).
} 
the complete month; the allocations to the Thai and Brazilian market are reduced quickly. During the last days of the month, the crisis conscious strategy advises to leave all markets, while the crisis ignorant strategy advises to leave only Japan and Thailand. Despite their high volatility, the other markets remain attractive. Because the differences between the allocations become smaller in absolute sense, the certainty equivalent return decreases slightly. The other months (August till December) confirm these findings. In August and September, the crisis conscious strategy advises neither to invest in the Korean market.

We conclude that the impact of short sales constraints on allocations can be large, particularly for high probabilities of a systemic crises. However, also if short sales constraints are imposed it remains economically important to take the possibility of a crisis into account.

[Figure 5 about here.]

[Figure 6 about here.]

\subsubsection{Portfolio turnover}

In this subsection we shortly discuss the portfolio turnover that results from the different strategies. We use this information to gauge the possible impact of transaction costs on our results. Though transaction costs are present in the real world and can seriously impact dynamic trading strategies (see e.g. Liu and Loewenstein, 2002; Balduzzi and Lynch, 1999), including transaction costs in the asset allocation problem would impede our analysis and is not our chief interest. Instead, we turn attention to the portfolio turnover of the different strategies as a measure of their variability. Higher variability typically leads to higher transaction costs. If the crisis conscious strategy leads to a higher portfolio turnover than the crisis ignorant strategy, introducing transaction costs will affect the crisis conscious allocations most.

We calculate the portfolio turnover by summing the absolute changes in the portfolio weights for the risky assets. Transactions costs will be a fraction of this measure, if transaction costs are proportional to the value of assets bought or sold. For the log utility 
investor, we find that the turnover in October 1997 equals 123.5 for the crisis conscious strategy versus 97.6 for the crisis ignorant strategy, 1.25 times as much, indicating that the crisis ignorant strategy is more stable. The turnover is large, but this is partly due to the assumption of log utility. In order to move to power utility, the log utility turnover should be divided by the coefficient of relative risk aversion. For the other months we calculate lower numbers, as the large drops during October lead to large adjustments of the portfolio weights. We interpret relatively small differences in turnover as evidence that our results are robust to transaction costs.

\section{Conclusions}

A systemic crisis in international equity markets can put investors in dire straits, because of the simultaneous decrease in expected returns and increase in volatilities and correlations. However, standard models supporting asset allocation decisions typically fail to fully capture systemic crises due to their irregular and relatively rare occurrences. In this paper, we have proposed a framework to determine the impact of systemic crises on asset allocations, which combines regime switching models with optimal portfolio construction in continuous time. In this framework, an investor can adopt a crisis conscious strategy that includes systemic crises, and, as an alternative, a crisis ignorant strategy which excludes it. We have studied the allocations of a US-based, global investor, who maximizes his expected utility by investing in equity markets in the US, Europe, Japan, Hong Kong, Thailand, Korea and Brazil, and a riskless asset. We have considered the case in which he has no information on the likelihood of the different states in the regime switching model, and the informative case of October 1997, which belongs to the Asian crisis. If the investor adopts the crisis conscious strategy, he shifts investments to countries that are less prone to a crisis, and tends to decrease the proportion of his wealth invested in risky assets. The calculation of certainty equivalent returns indicates that these differences are economically important. The investor requires a substantial compensation for incorrectly adopting the crisis ignorant strategy in the uninformative case, and this compensation rises 
quickly during October 1997.

The pronounced portfolio differences and their economic importance indicate that persistence is an important characteristic of systemic crises. We have estimated that the probability of remaining in the crisis regime for another month equals 0.90. Because of this persistence, we find stronger evidence advocating the incorporation of systemic crises in asset allocation decisions than reported by Das and Uppal (2004, 2003), while the corresponding unconditional probabilities on a crisis are similar (0.045 versus 0.0501$)$. Crisis persistence also explains the large differences between the crisis conscious and ignorant strategies and the large required compensation if a crisis occurs with almost certainty. This would also explain the well-known fact that investors stay away from financial markets after a systemic crises for a relatively long period of time.

We also find that systemic crises seriously diminish diversification possibilities. If a crisis has a small probability of occurrence, this effect is present but limited. As the probability increases, the impact becomes larger and leads to short positions in several markets. When the investors faces short sales constraints, he withdraws from equity markets completely. These findings are complementary to Ang and Bekaert (2002) who conclude that the presence of a bear regime in a regime switching model does not extinguish diversification possibilities. However, because of its severity the crisis regime in our model causes a much stronger deterioration in the risk-return trade-off than the bear regime in their model.

This paper can motivate further research in several ways. Some parts of our model are kept at a basic level for clarity. It would be interesting, however, to see the influence of a crisis when other economic variables are used to predict the likelihood of a crisis or the corresponding means and variances. A more normative model for a crisis can also be interesting. Our finding that crisis conscious strategies shift allocations from countries that are relatively prone to a crisis to countries that are less prone to it can add to the research on the home bias puzzle (see Lewis, 1999, for an overview), particularly in relation to emerging markets. These are issues for future research. 


\section{A Appendix}

\section{A.1 A multinomial model for regime transition probabilities}

In this appendix we discuss the specification of the multinomial logistic model that we propose for the regime transition probabilities in Section 2.1 in more detail. The probability $\pi_{i}^{a b}$ gives the marginal probability that asset $i$ will switch to regime $Q_{i}^{a}$, given that the current regime is $\tilde{Q}^{b}$, and that a crisis is absent in both the current and the destination regime, and has functional form:

$$
\pi_{i}^{a b}=\frac{\exp f\left(Q_{i}^{a}, Q^{b}\right)}{1+\sum_{k=1}^{K-1} \exp f\left(Q_{i}^{a}=k, Q^{b}\right)}
$$

The summation in the denominator excludes the $K^{\text {th }}$ basic regime to ensure that the probabilities add up to 1 . We specify the function $f\left(Q_{i}^{a}, Q^{b}\right)$ as follows:

$$
f\left(Q_{i}^{a}=k, Q^{b}\right)=\psi_{i, k, Q_{i}^{b}}+\sum_{j=1, j \neq i}^{n} \sum_{k^{\prime}=2}^{K} \psi_{i, j, k, k^{\prime}} I\left(Q_{j}^{b}=k^{\prime}\right),
$$

where $\psi_{i, k, Q_{i}^{b}}$ and $\psi_{i, j, k, k^{\prime}}$ are constant, and $I()$ denotes the indicator function that returns one if the statement in parentheses evaluates to true and zero otherwise. If all assets other than asset $i$ are in their low volatility regimes $\left(Q_{j}^{b}=1\right)$, the function returns the constant $\psi_{i, k, Q_{j}^{b}}$. For the assets that are in a higher volatility level $k^{\prime}$, constants $\psi_{i, j, k^{\prime}}$ are added to it. We require $\psi_{i, j, k, k^{\prime}}<0$ for $k<k^{\prime}, \psi_{i, j, k, k^{\prime}}>0$ for $k \geq k^{\prime}$, and $\psi_{i, j, k, k^{\prime}}<\psi_{i, j, k, k^{\prime \prime}}$ for $k^{\prime}<k^{\prime \prime}$ to ensure that the volatility spill-over effects increase the probability of higher volatility regimes.

\section{A.2 Short sales constraints}

Short sales constraints can be included in the asset allocation problem straightforwardly. The basic optimization problem, constituted by constituted by Eq. (7) and Eq. (10) is now extended with short sales constraints $\phi_{i, t} \geq 0, \forall t, i=1, \ldots, n$. The new first order conditions for optimality include Kuhn-Tucker conditions for the new restrictions. To 
derive these we start with the Hamilton-Jacobi-Bellman equation (13), combined with the guess for the indirect utility function (14):

$$
\max _{\phi}\left(\frac{\partial C(t)}{\partial t} \frac{W^{1-\gamma}}{1-\gamma}+\left(r_{f}+\phi^{\prime} \alpha\right) W^{1-\gamma}-\frac{1}{2} \gamma \phi^{\prime} \Omega \phi W^{1-\gamma}\right)=0,
$$

where $\alpha \equiv \mu+\frac{1}{2} \operatorname{diag}(\Omega)-r_{f} \iota_{n}$. We introduce Lagrange multipliers $\lambda_{i, t} \geq 0 \forall t$ for the short sales constraint on asset $i$ and construct a Lagrangian function by adding the term $\phi^{\prime} \lambda$ to the maximand in the HJB-equation. Differentiation yields the following first order conditions:

$$
\begin{aligned}
\alpha-\gamma \Omega \phi & =-\lambda W^{-(1-\gamma)} \\
\phi_{i} \lambda_{i} & =0 \\
\phi_{i}, \lambda_{i} & \geq 0
\end{aligned}
$$

where the last two restrictions are the complementary slackness conditions.

This system of (in)equalities resembles the system of (in)equalities resulting from a mean-variance portfolio optimization problem with short sales constraints (see Teplá, 2000; de Roon et al., 2001). Consequently, the optimal portfolio can also be characterized similarly. Let $I^{p}$ be the set of indices for which the short selling constraints are not binding, and use the superscript ${ }^{p}$ to denote the subvectors and submatrices with respect to that set. The optimal positive weights are given by:

$$
\phi^{p}=\gamma^{-1}\left(\Omega^{p}\right)^{-1} \alpha^{p}
$$

The Lagrange multipliers for the assets in the complement $I^{\circ}$ of $I^{p}$ can be found as:

$$
\lambda^{\circ}=\left(-\alpha^{\circ}+\gamma \Omega^{\circ p} \phi^{p}\right) W^{1-\gamma}=\left(-\alpha^{\circ}+\Omega^{\circ p}\left(\Omega^{p}\right)^{-1} \alpha^{p}\right) W^{1-\gamma} \geq 0
$$

where $\Omega^{\circ p}$ denotes the $n^{\circ} \times n^{p}$ covariance matrix of the returns of the assets in $I^{\circ}$ with those in $I^{p}$. Using positivity of wealth, a partition of the assets into subsets $I^{p}$ and $I^{\circ}$ is valid if and only if $-\alpha^{\circ}+\Omega^{\circ p}\left(\Omega^{p}\right)^{-1} \alpha^{p} \geq 0$. In general, the validity of a partition will have to be checked using this condition. However, it easy is to verify that assets $i$ for which $\alpha_{i} \leq 0$ and $\Omega_{i j} \geq 0 \forall j$ will always be in $I^{\circ}$. 


\section{References}

Alexander, C. and Narayanan, S. (2001). Option pricing with normal mixture returns. Working paper 2001-10, ISMA Centre, University of Reading, Reading, UK.

Alexander, C. and Scourse, A. (2004). Bivariate normal mixture spread option valuation. Quantitative Finance, 4(6):637-648.

Ang, A. and Bekaert, G. (2002). International asset allocation with regime shifts. Review of Financial Studies, 15(4):1137-1187.

Ang, A. and Bekaert, G. (2004). How regimes affect asset allocation. Financial Analysts Journal, 60(2):86-99.

Ang, A. and Chen, J. (2002). Asymmetric correlations of equity portfolios. Journal of Financial Economics, 63(3):443-494.

Bae, K.-H., Karolyi, A., and Stulz, R. M. (2003). A new approach to measuring financial contagion. Review of Financial Studies, 16(3):717-763.

Baele, L. (2005). Volatility spillover effects in european equity markets: Evidence from a regime-switching model. Journal of Financial and Quantitative Analysis, 40(2).

Baig, T. and Goldfajn, I. (1999). Financial market contagion in the asian crisis. International Monetary Fund Staff Papers, 46(2):167-195.

Balduzzi, P. and Lynch, A. W. (1999). Transaction costs and predictability: Some utility cost calculations. Journal of Financial Economics, 52(1):47-78.

Bekaert, G. and Harvey, C. R. (1997). Emerging equity market volatility. Journal of Financial Economics, 43(1):29-77.

Bekaert, G. and Harvey, C. R. (2003). Emerging markets finance. Journal of Empirical Finance, 10(1):3-55. 
Bertero, E. and Mayer, C. (1990). Structure and performance: Global interdependence of stock markets around the crash of October 1987. European Economic Review, 34(6):1155-1180.

Boyer, B. H., Gibson, M. S., and Loretan, M. (1999). Pitfalls in tests for changes in correlations. International Finance Discussion Papers Nr. 597, Board of Governors of the Federal Reserve System.

Brigo, D. (2002). The general mixture-diffusion SDE and its relationship with uncertainvolatility option model with volatility-asset decorrelation. Working paper, Banca IMI, Milan, Italy; available at http://www.damianobrigo.it/sdesmixtures.pdf.

Brigo, D. and Mercurio, F. (2002). Lognormal-mixture dynamics and calibration to market volatility smiles. International Journal of Theoretical and Applied Finance, 5(4):427-446.

Calvo, S. and Reinhart, C. (1996). Capital flows to latin america : Is there evidence of contagion effects? In Calvo, G., Goldstein, M., and Hochreiter, E., editors, Private Capital Flows to Emerging Markets. Institute for International Economics, Washington, DC, USA.

Campbell, R. A., Koedijk, C. G., Forbes, C. S., and Kofman, P. (2003). Diversification meltdown or the impact of fat tails on conditional correlation? Working paper, University of Technology, Sydney, Australia.

Campbell, R. A., Koedijk, C. G., and Kofman, P. (2002). Increased correlation in bear markets. Financial Analysts Journal, 58(1):87-94.

Corsetti, G., Pericoli, M., and Sbracia, M. (2005). 'Some contagion, some interdependence' more pitfalls in tests of financial contagion. Journal of International Money $\&$ Finance, forthcoming.

Das, S. R. and Uppal, R. (2003). Systemic risk and international portfolio choice. Working paper, Santa Clara University, Santa Clara, CA, USA. 
Das, S. R. and Uppal, R. (2004). Systemic risk and international portfolio choice. The Journal of Finance, 59(6):2809-2834.

De Bandt, O. and Hartmann, P. (2000). Systemic risk: A survey. Working paper 2634, CEPR, London, UK.

de Roon, F. A., Nijman, T. E., and Werker, B. J. (2001). Testing for mean-variance spanning with short sales constraints and transaction costs: The case of emerging markets. The Journal of Finance, 56(2):721-742.

Dempster, A. P., Laird, N. M., and Rubin, D. B. (1977). Maximum likelihood from incomplete data via the EM algorithm. Journal of the Royal Statistical Society: Series $B, 39(1): 1-38$.

Dow, J. (2000). What is sytemic risk? Moral hazard, initial shocks and propagation. Monetary and Economic Studies, 18(2):1-24.

Edwards, S. and Susmel, R. (2001). Volatility dependence and contagion in emerging equity markets. Journal of Development Economics, 66(2):505-532.

Forbes, K. and Rigobon, R. (2002). No contagion, only interdependence: Measuring stock market co-movements. Journal of Finance, 57(5):2223-2261.

Graflund, A. and Nilsson, B. (2003). Dynamic portfolio selection: The relevance of switching regimes and investment horizon. European Financial Management, 9(2):179-200.

Hamao, Y., Masulis, R. W., and Ng, V. (1990). Correlations in price changes and volatility across international stock markets. Review of Financial Studies, 3(2):281-307.

Hamilton, J. D. (1990). Analysis of time series subject to changes in regime. Journal of Econometrics, 45(1-2):39-70.

Hamilton, J. D. (1994). Time Series Analysis. Princeton University Press, Princeton, New Jersey. 
Hamilton, J. D. and Susmel, R. (1994). Autoregressive conditional heteroskedasticity and changes in regime. Journal of Econometrics, 64:307-333.

Hansen, B. E. (1992). The likelihood ratio test under nonstandard conditions: Testing the markov switching model of GNP. Journal of Applied Econometrics, 7(Supplement):S61$\mathrm{S} 82$.

Harvey, C. R. (1995). Predictable risk and returns in emerging markets. Review of Financial Studies, 8(3):773-816.

Kamin, S. B. (1999). The current international financial crisis: How much is new? Journal of International Money and Finance, 18:501-514.

Kaminsky, G. L. and Reinhart, C. M. (2002). Financial markets in times of stress. Journal of Development Economics, 69(2):451-470.

Kaminsky, G. L. and Schmukler, S. L. (1999). What triggers market jitters? A chronicle of the asian crisis. Journal of International Money and Finance, 18(4):537-560.

King, M. A. and Wadhwani, S. (1990). Transmission of volatility between stock markets. The Review of Financial Studies, 3(1):5-33.

Lee, B.-S., Meng-Rui, O., and Wang, S. S. (2004). Information transmission between the NASDAQ and asian second board markets. Journal of Banking Ef Finance, 28(7):16371670 .

Léonard, D. and Van Long, N. (1992). Optimal Control Theory and Static Optimization in Economics. Cambridge University Press, Cambridge, UK.

Lewis, K. K. (1999). Trying to explain home bias in equities and consumption. Journal of Economic Literature, 37(2):571-608.

Liu, H. and Loewenstein, M. (2002). Optimal portfolio selection with transaction costs and finite horizons. Review of Financial Studies, 15(3):805-835. 
Liu, J., Longstaff, F. A., and Pan, J. (2003). Dynamic asset allocation with event risk. The Journal of Finance, 58(1):231-259.

Longin, F. M. (1996). The asymptotic distribution of extreme stock market returns. Journal of Business, 69(3):383-408.

Longin, F. M. and Solnik, B. (2001). Extreme correlation of international equity markets. The Journal of Finance, 56(2):649-676.

Loretan, M. and English, W. B. (2000). Evaluating "correlation breakdowns" during periods of market volatility. International Finance Discussion Papers Nr. 658, Board of Governors of the Federal Reserve System.

Merton, R. C. (1969). Lifetime portfolio selection under uncertainty: The continuous time case. Review of Economics and Statistics, 51:247-57. Republished as Ch. 4 in Merton, R.C. (1990), Continuous-time Finance, Basil Blackwell Publishers, Cambridge, MA, USA.

Merton, R. C. (1971). Optimum consumption and portfolio rules in a continuous-time model. Journal of Economic Theory, 3:373-413. Republished as Ch. 5 in Merton, R.C. (1990), Continuous-time Finance, Basil Blackwell Publishers, Cambridge, MA, USA.

Ng, A. (2000). Volatility spillover effects from Japan and the US to the Pacific-Basin. Journal of International Money and Finance, 19(2):207-233.

Ramchand, L. and Susmel, R. (1998). Volatility and cross correlation across major stock markets. Journal of Empirical Finance, 5(4):397-416.

Roll, R. (1988). The international crash of October 1987. Financial Analysts Journal, 44(5):19-35.

Roll, R. (1989). Price volatility, international market links, and their implications for regulatory policies. Journal of Financial Services Research, 3(2-3):211-246. 
Susmel, R. (2001). Extreme observations and diversification in Latin American emerging equity markets. Journal of International Money and Finance, 20:971-986.

Teplá, L. (2000). Optimal portfolio policies with borrowing and shortsale constraints. Journal of Economic Dynamics $\&$ Control, 24(11-12):1623-1639.

Timmermann, A. (2000). Moments of markov switching models. Journal of Econometrics, 96(1):75-111. 
(a) univariate statistics

\begin{tabular}{lccccccc}
\hline & US & Europe & Japan & Hong Kong & Thailand & Korea & Brazil \\
\hline mean & 0.50 & 0.53 & 0.31 & 0.69 & 0.31 & 0.41 & 0.32 \\
volatility & 4.38 & 4.75 & 6.48 & 9.31 & 10.22 & 10.54 & 15.42 \\
skewness & -0.76 & -0.72 & 0.07 & -1.08 & -0.44 & 0.36 & -0.49 \\
kurtosis & 5.98 & 4.78 & 3.48 & 8.43 & 6.01 & 5.81 & 6.01 \\
minimum & -24.45 & -21.65 & -22.18 & -57.58 & -41.88 & -41.37 & -84.79 \\
maximum & 12.05 & 12.69 & 21.04 & 28.37 & 38.14 & 53.17 & 44.84 \\
\hline
\end{tabular}

(b) correlation matrix

\begin{tabular}{lccccccc}
\hline & US & Europe & Japan & Hong Kong & Thailand & Korea & Brazil \\
\hline US & 1 & 0.64 & 0.30 & 0.42 & 0.32 & 0.28 & 0.21 \\
Europe & 0.64 & 1 & 0.48 & 0.50 & 0.31 & 0.25 & 0.25 \\
Japan & 0.30 & 0.48 & 1 & 0.30 & 0.25 & 0.37 & 0.15 \\
Hong Kong & 0.42 & 0.50 & 0.30 & 1 & 0.39 & 0.21 & 0.21 \\
Thailand & 0.32 & 0.31 & 0.25 & 0.39 & 1 & 0.39 & 0.13 \\
Korea & 0.28 & 0.25 & 0.37 & 0.21 & 0.39 & 1 & 0.12 \\
Brazil & 0.21 & 0.25 & 0.15 & 0.21 & 0.13 & 0.12 & 1 \\
\hline
\end{tabular}

Table 1: Descriptive statistics for the data set consisting of the monthly excess gross returns (in \%) for the MSCI US, MSCI Europe, MSCI Japan, MSCI Hong Kong, IFC Thailand, IFC Korea and IFC Brazil indexes, running from January 1976 to December 2004. Panel (a) presents univariate statistics, panel (b) shows the correlation matrix. 


\begin{tabular}{|c|c|c|c|c|c|c|}
\hline & & \multicolumn{2}{|c|}{ crisis ignorant } & \multicolumn{3}{|c|}{ crisis conscious } \\
\hline & & low & high & low & high & crisis \\
\hline \multirow[t]{3}{*}{ US } & $\mu$ & 0.90 & 0.35 & 0.95 & 0.47 & -0.16 \\
\hline & $\sqrt{\omega}$ & 2.47 & 4.99 & 2.21 & 4.73 & 4.97 \\
\hline & & & & & & 1.00 \\
\hline \multirow[t]{3}{*}{$\mathrm{EU}$} & $\mu$ & 1.10 & 0.23 & 1.17 & 0.26 & -0.30 \\
\hline & $\sqrt{\omega}$ & 3.09 & 5.46 & 3.07 & 5.35 & 5.52 \\
\hline & & & & & & 0.88 \\
\hline \multirow[t]{3}{*}{ Japan } & $\mu$ & 0.44 & 0.03 & 0.20 & 0.74 & -1.46 \\
\hline & $\sqrt{\omega}$ & 5.14 & 8.29 & 4.92 & 8.26 & 9.83 \\
\hline & & & & & & 3.47 \\
\hline \multirow[t]{3}{*}{ Hong Kong } & $\mu$ & 0.93 & 0.57 & 0.92 & 0.74 & -2.15 \\
\hline & $\sqrt{\omega}$ & 6.00 & 13.34 & 5.77 & 12.98 & 14.75 \\
\hline & & & & & & 4.55 \\
\hline \multirow[t]{3}{*}{ Thailand } & $\mu$ & 0.80 & -0.53 & -0.22 & 1.51 & -7.03 \\
\hline & $\sqrt{\omega}$ & 6.29 & 15.28 & 5.24 & 11.44 & 23.62 \\
\hline & & & & & & 13.46 \\
\hline \multirow[t]{3}{*}{ Korea } & $\mu$ & 0.34 & 1.28 & 0.19 & 1.94 & -6.55 \\
\hline & $\sqrt{\omega}$ & 7.26 & 15.69 & 6.56 & 12.44 & 24.04 \\
\hline & & & & & & 13.40 \\
\hline \multirow[t]{5}{*}{ Brazil } & $\mu$ & 0.96 & -0.73 & 0.86 & -0.01 & -2.43 \\
\hline & $\sqrt{\omega}$ & 9.83 & 20.91 & 8.49 & 19.49 & 20.35 \\
\hline & & & & & & 3.81 \\
\hline & $\mu_{c}$ & & & & & -0.63 \\
\hline & $\sqrt{\omega_{c}}$ & & & & & 1.54 \\
\hline
\end{tabular}

Table 2: Parameter estimates. This tables reports the estimates for the mean parameters $(\mu)$ and volatility parameters $(\sqrt{\omega})$ of the marginal distributions of the excess monthly equity return (in \%) for the US, Europe Japan, Hong Kong, Thailand Korea and Brazil under the low and high volatility regimes. The first two columns present the estimates for the crisis ignorant strategy; the second two for the crisis conscious strategy. The parameters for the crisis conscious strategy also contain estimates for the shock: a mean $\left(\mu_{c}\right)$ and variance $\left(\sqrt{\omega_{c}}\right)$. The last column contains the estimates for the sensitivity to a systemic crisis $(\delta)$ and the resulting mean and volatility. The sensitivity of the US market has been normalized to 1 . 
(a) crisis ignorant

\begin{tabular}{cccccccc}
\hline & US & EU & JP & HK & TH & KO & BR \\
\hline US & 1 & 0.65 & 0.29 & 0.46 & 0.28 & 0.27 & 0.23 \\
EU & 0.65 & 1 & 0.48 & 0.53 & 0.30 & 0.27 & 0.27 \\
JP & 0.29 & 0.48 & 1 & 0.32 & 0.18 & 0.38 & 0.15 \\
HK & 0.46 & 0.53 & 0.32 & 1 & 0.35 & 0.22 & 0.25 \\
TH & 0.28 & 0.30 & 0.18 & 0.35 & 1 & 0.24 & 0.11 \\
KO & 0.27 & 0.27 & 0.38 & 0.22 & 0.24 & 1 & 0.13 \\
BR & 0.23 & 0.27 & 0.15 & 0.25 & 0.11 & 0.13 & 1 \\
\hline
\end{tabular}

(b) crisis conscious

\begin{tabular}{cccccccc}
\hline & US & EU & JP & HK & TH & KO & BR \\
\hline US & 1 & 0.64 & 0.30 & 0.47 & 0.33 & 0.26 & 0.24 \\
EU & 0.64 & 1 & 0.49 & 0.54 & 0.32 & 0.26 & 0.27 \\
JP & 0.30 & 0.49 & 1 & 0.32 & 0.15 & 0.35 & 0.16 \\
HK & 0.47 & 0.54 & 0.32 & 1 & 0.37 & 0.21 & 0.26 \\
TH & 0.33 & 0.32 & 0.15 & 0.37 & 1 & 0.21 & 0.10 \\
KO & 0.26 & 0.26 & 0.35 & 0.21 & 0.21 & 1 & 0.14 \\
BR & 0.24 & 0.27 & 0.16 & 0.26 & 0.10 & 0.14 & 1 \\
\hline
\end{tabular}

(c) crisis regime

\begin{tabular}{cccccccc}
\hline & US & EU & JP & HK & TH & KO & BR \\
\hline US & 1 & 0.67 & 0.41 & 0.54 & 0.42 & 0.39 & 0.31 \\
EU & 0.67 & 1 & 0.53 & 0.57 & 0.37 & 0.34 & 0.32 \\
JP & 0.41 & 0.53 & 1 & 0.49 & 0.53 & 0.62 & 0.28 \\
HK & 0.54 & 0.57 & 0.49 & 1 & 0.57 & 0.50 & 0.36 \\
TH & 0.42 & 0.37 & 0.53 & 0.57 & 1 & 0.80 & 0.30 \\
KO & 0.39 & 0.34 & 0.62 & 0.50 & 0.80 & 1 & 0.32 \\
BR & 0.31 & 0.32 & 0.28 & 0.36 & 0.30 & 0.32 & 1 \\
\hline
\end{tabular}

Table 3: Estimates for the correlations between the different countries for the crisis ignorant (panel a) and crisis conscious strategy (panel b) and the resulting correlations for the crisis regime (panel c). The correlations are assumed to be independent of the basic regimes. 


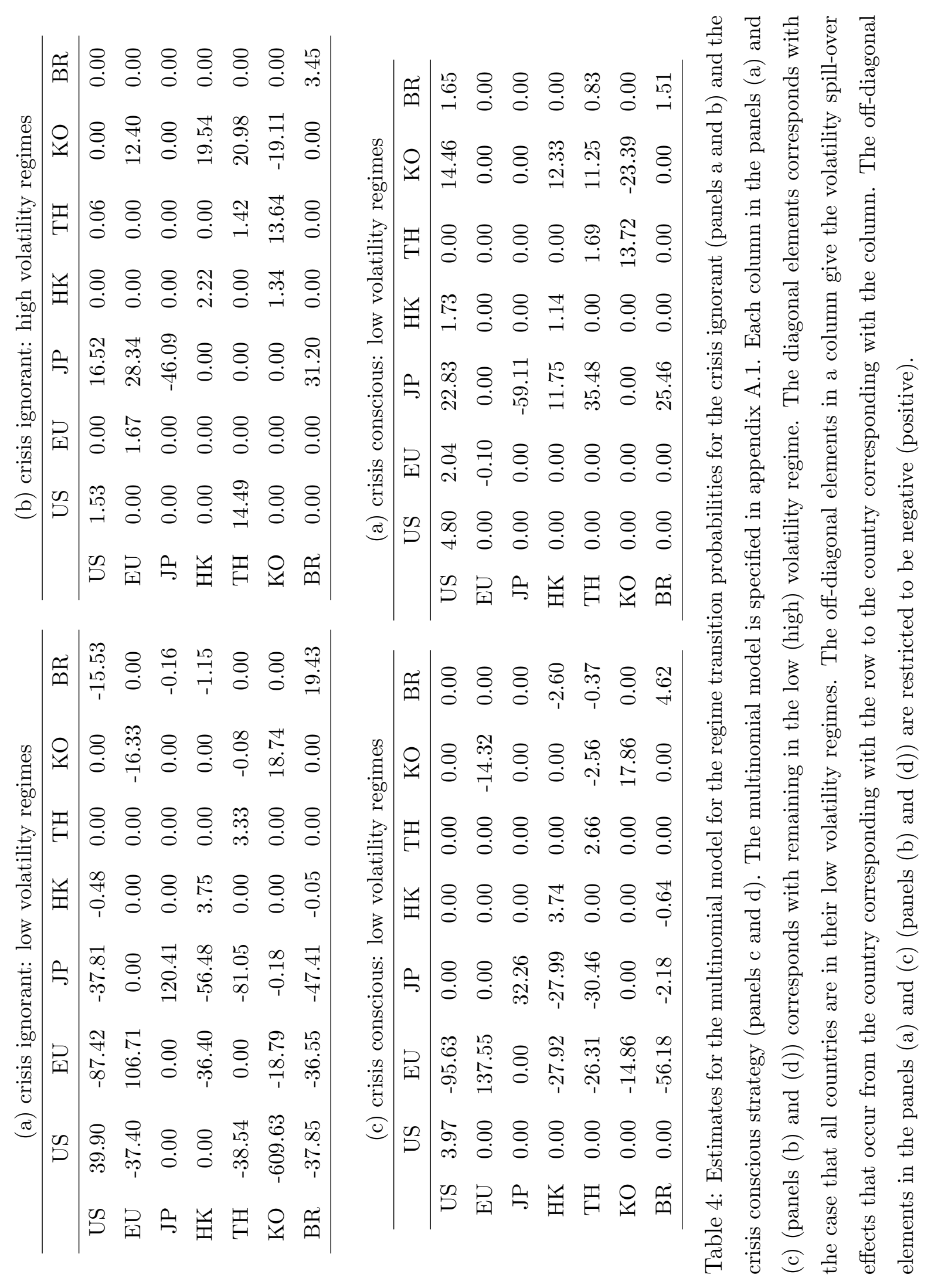




\begin{tabular}{|c|c|c|c|c|c|c|c|c|}
\hline & \multicolumn{4}{|c|}{ log utility portfolio } & \multicolumn{4}{|c|}{ risky assets portfolio } \\
\hline & $\begin{array}{c}\text { crisis } \\
\text { ignorant }\end{array}$ & $\begin{array}{c}\text { crisis } \\
\text { conscious }\end{array}$ & $\phi^{e}$ & $\phi^{s}$ & $\begin{array}{c}\text { crisis } \\
\text { ignorant }\end{array}$ & $\begin{array}{c}\text { crisis } \\
\text { conscious }\end{array}$ & $\phi^{e}$ & $\phi^{s}$ \\
\hline US & 1.61 & 1.15 & -0.68 & 0.22 & 0.28 & 0.24 & -0.11 & 0.06 \\
\hline Europe & 3.59 & 2.98 & -1.06 & 0.44 & 0.63 & 0.62 & -0.15 & 0.14 \\
\hline Japan & -0.70 & -0.39 & 0.45 & -0.13 & -0.12 & -0.08 & 0.07 & -0.03 \\
\hline Hong Kong & 0.26 & 0.27 & 0.08 & -0.07 & 0.05 & 0.06 & 0.02 & -0.01 \\
\hline Thailand & 0.02 & 0.07 & 0.55 & -0.50 & 0.00 & 0.01 & 0.10 & -0.09 \\
\hline Korea & 0.60 & 0.44 & 0.30 & -0.46 & 0.11 & 0.09 & 0.06 & -0.08 \\
\hline Brazil & 0.33 & 0.27 & -0.03 & -0.03 & 0.06 & 0.06 & 0.00 & 0.00 \\
\hline risk free & -4.71 & -3.79 & 0.40 & 0.52 & 0 & 0 & 0 & 0 \\
\hline
\end{tabular}

Table 5: Optimal portfolios for the crisis ignorant and crisis conscious strategies for different situations: log utility and an investment in risky assets only. The portfolios are the initial portfolios $(t=0)$ based on the unconditional inference probabilities. The portfolio weights for the different countries and the risk-free asset are reported in the first two columns. The differences between the allocations are decomposed in an estimation effect $\phi^{e}$ and a crisis effect $\phi^{s}$. 


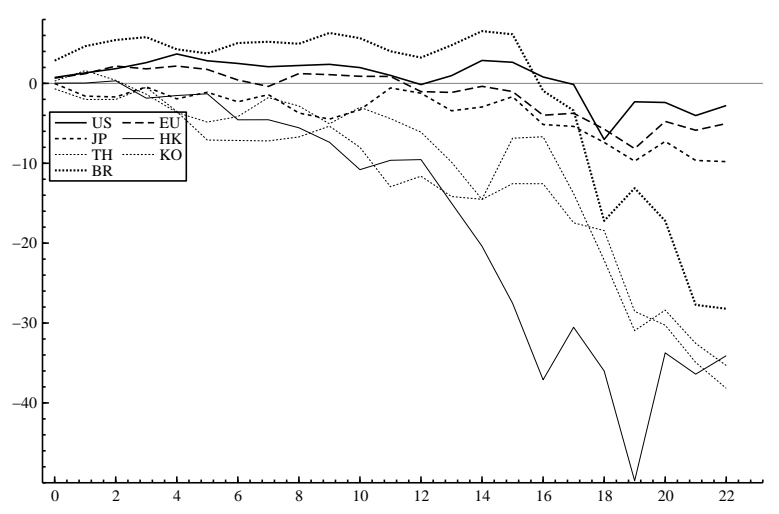

(a) return path

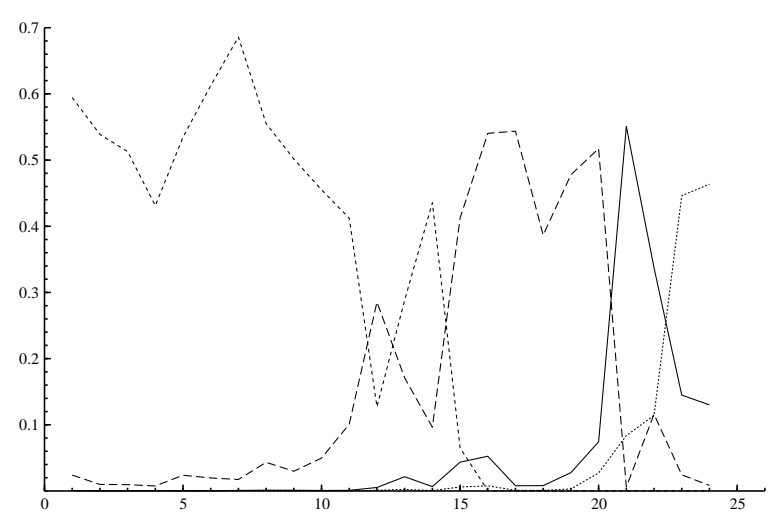

(c) ignorant

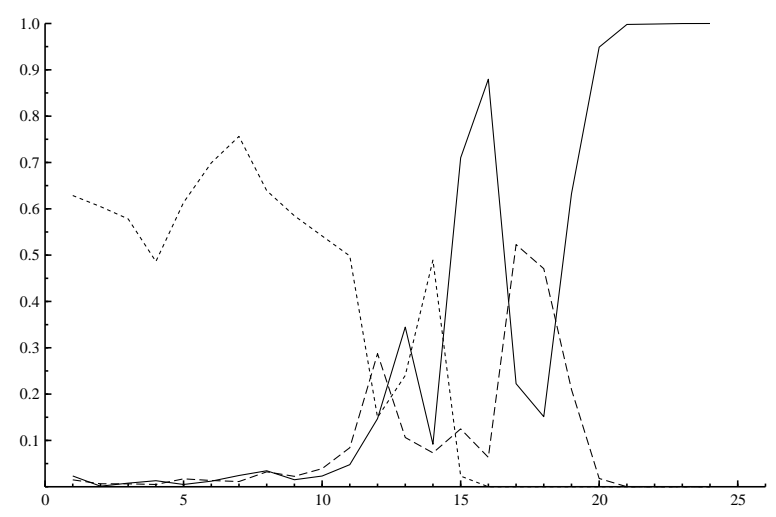

(b) conscious

Figure 1: The return path (excess returns, in \%) of the indexes for the US, Europe (EU), Japan (JP), Hong Kong (HK), Thailand (TH), Korea (KO) and Brazil (BR) (panel a) and the resulting inferences for the crisis conscious strategy (panel b) and the crisis ignorant strategy (panel c) for each trading day in October 1997 (numbered consecutively). The inference probabilities are constructed by updating the forecast probabilities based on the returns to September 1997 in a Bayesian fashion as given in Eq. (17). We only plot the inferences for a state vector, if the inferences have exceeded 0.4 at least once: for the crisis conscious strategy that is US and Thailand high volatility, others low (dashed line), US, Hong Kong and Thailand high volatility, others low (long dashed line), and the crisis state (solid line); for the crisis ignorant strategy that is US and Thailand high volatility, others low (dashed line), US, Hong Kong and Thailand high volatility, others low (long dashed line), US, Europe, Hong Kong, Thailand and Korea high volatility, others low (solid line) and the state in which all countries have high volatility (dotted line). 


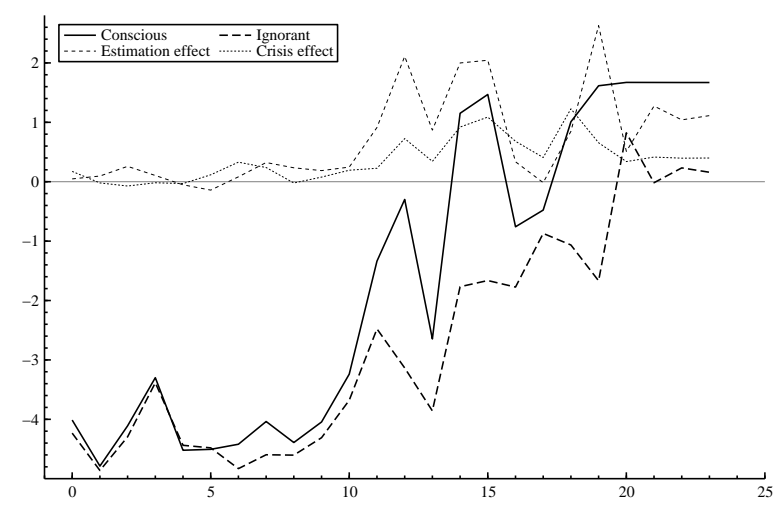

(a) US

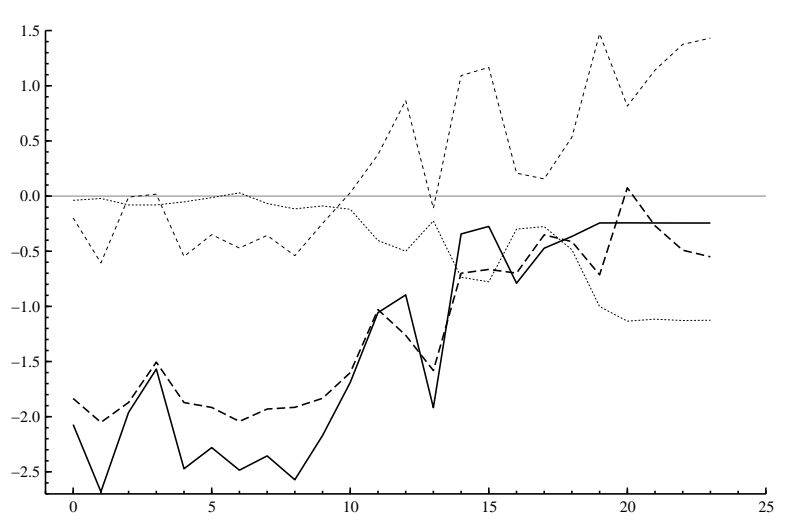

(c) Japan

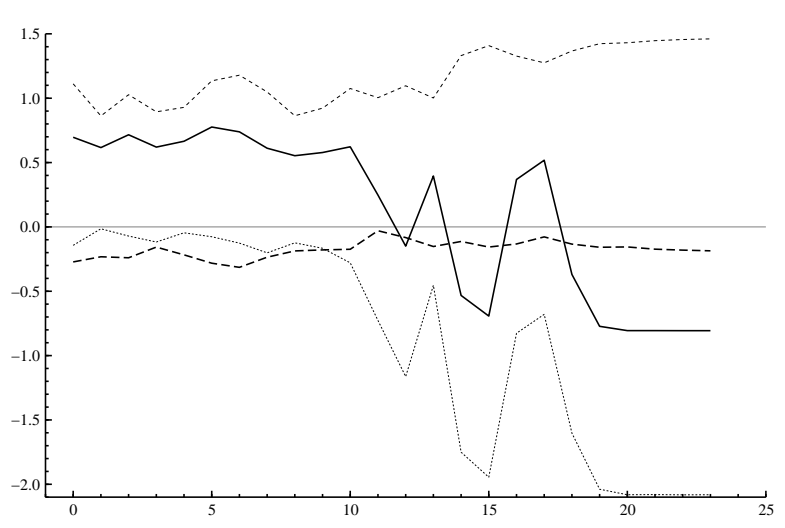

(e) Thailand

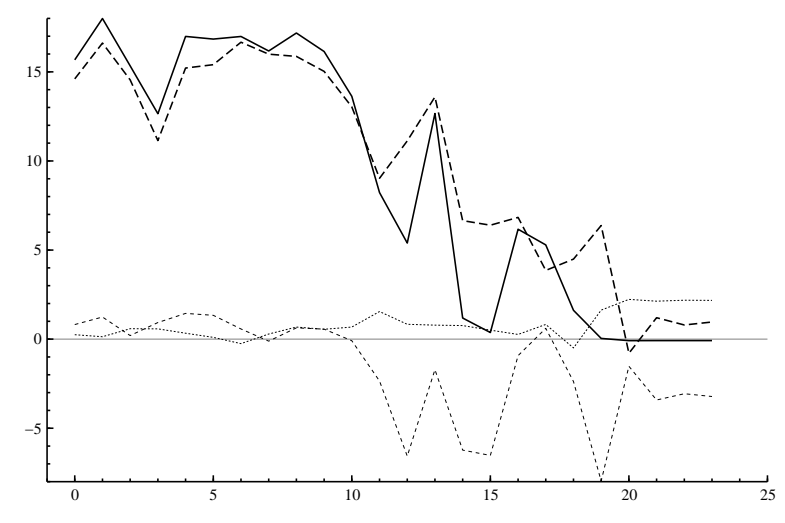

(b) $\mathrm{EU}$

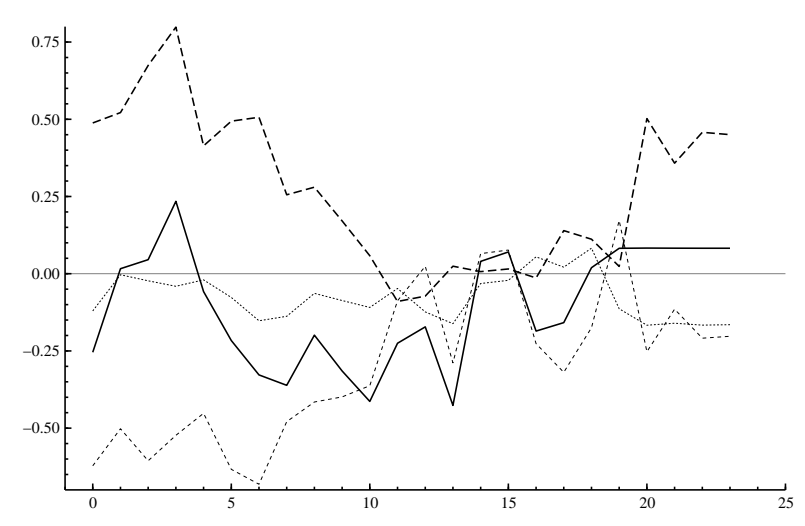

(d) Hong Kong

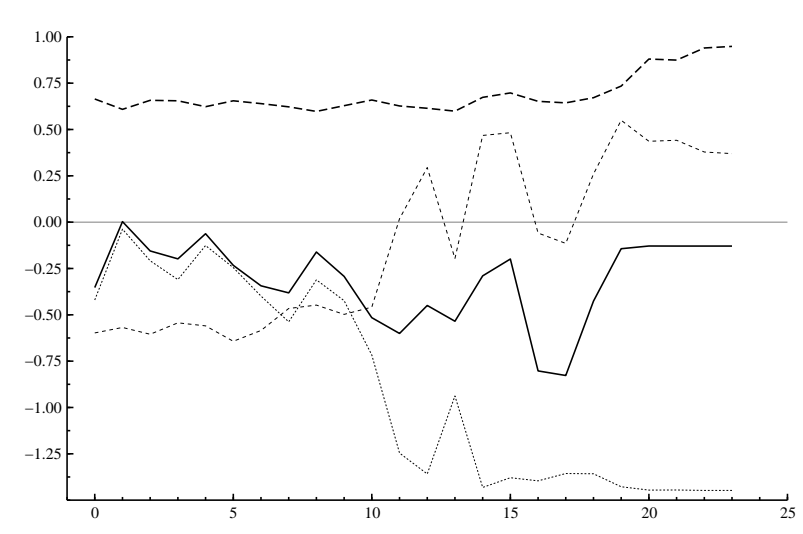

(f) Korea 


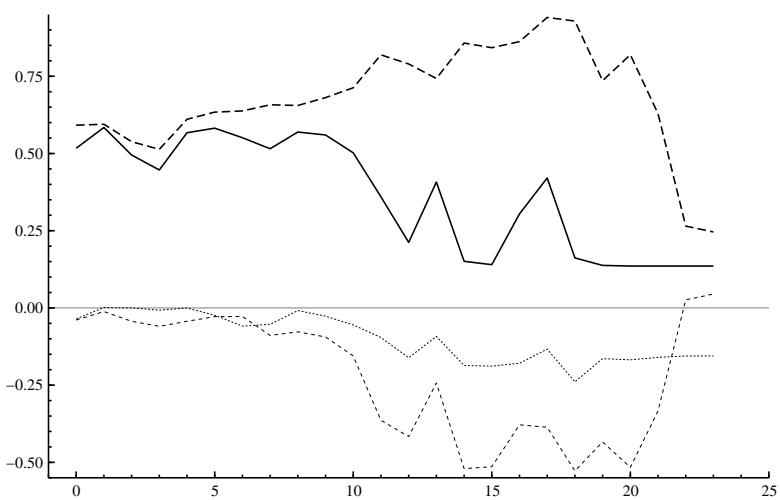

(g) Brazil

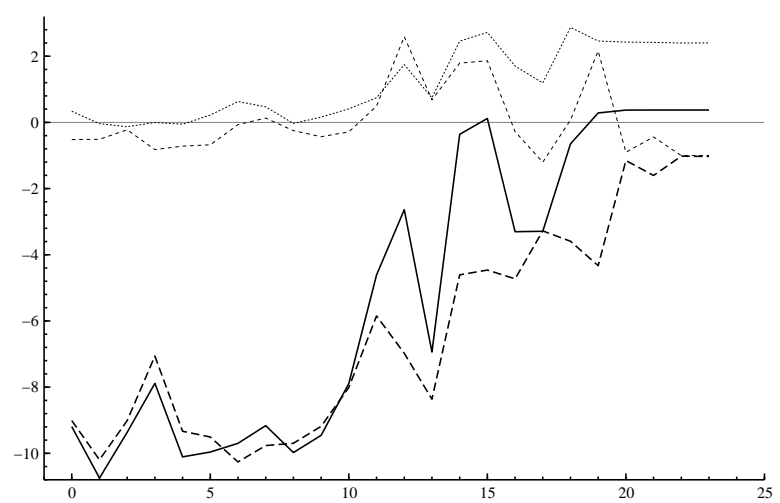

(h) risk free asset

Figure 2: The proportion invested in the different countries for the crisis conscious and crisis ignorant strategy and a decomposition of the differences for each trading day in October 1997 (numbered consecutively). We assume the investor has a log utility function. The portfolios are based on the estimates in Tables 2 and 3 and the inference probabilities that are constructed by updating the forecast probabilities based on the returns to September 1997 in a Bayesian fashion as given in Eq. (17). The portfolio differences between the two portfolios are decomposed in an estimation and a crisis effect . 


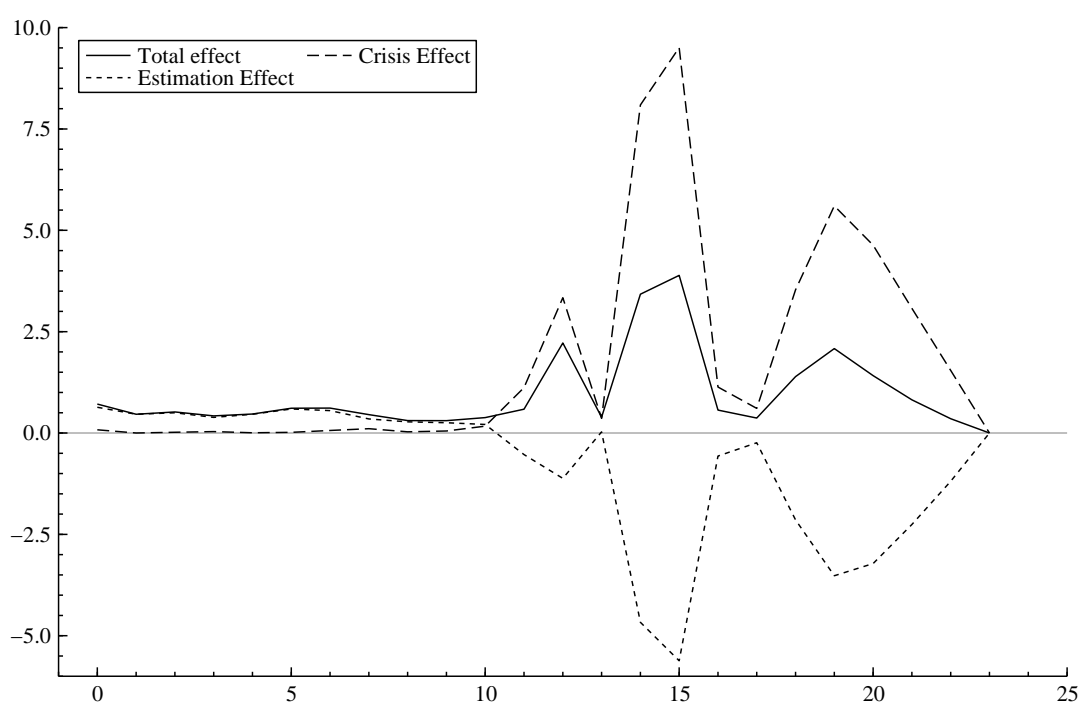

Figure 3: Certainty equivalent return (in \%) needed to compensate the investor for adopting the suboptimal ignorant strategy and a decomposition in an estimation and crisis effect for each trading day in October 1997 (numbered consecutively). We assume the investor has a log utility function and a horizon of 1 month. The portfolios during October 1997 and the corresponding decompositions are given in Figure 2. 


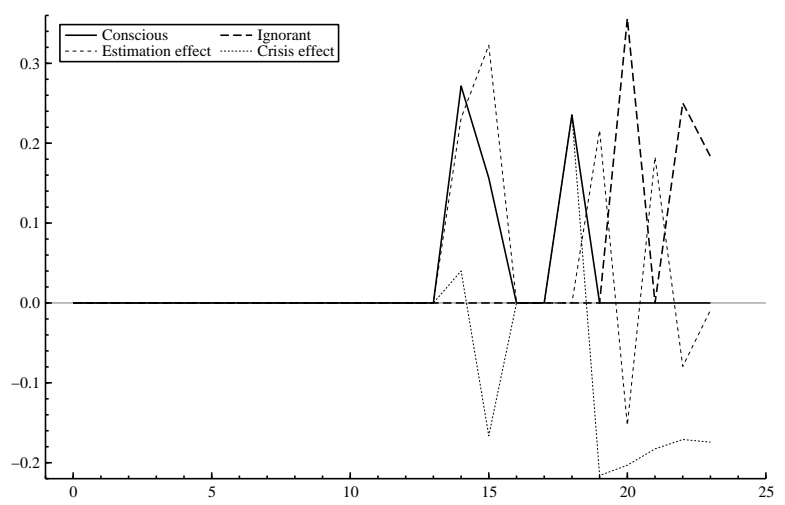

(a) US

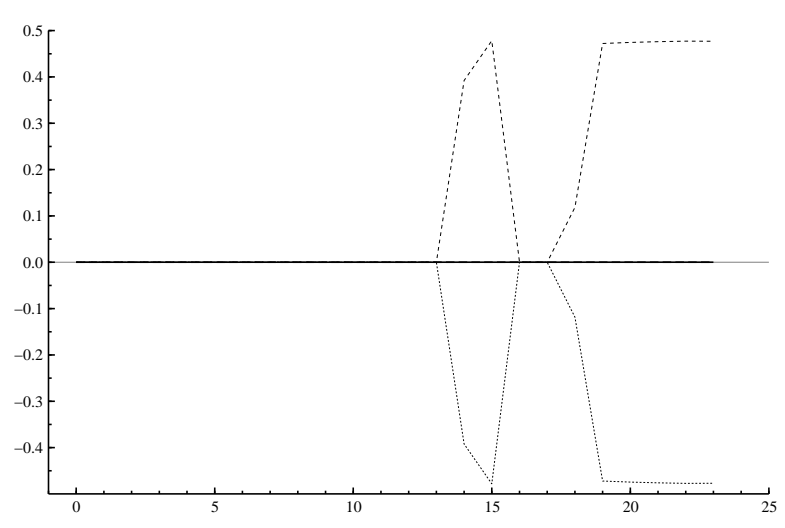

(c) Japan

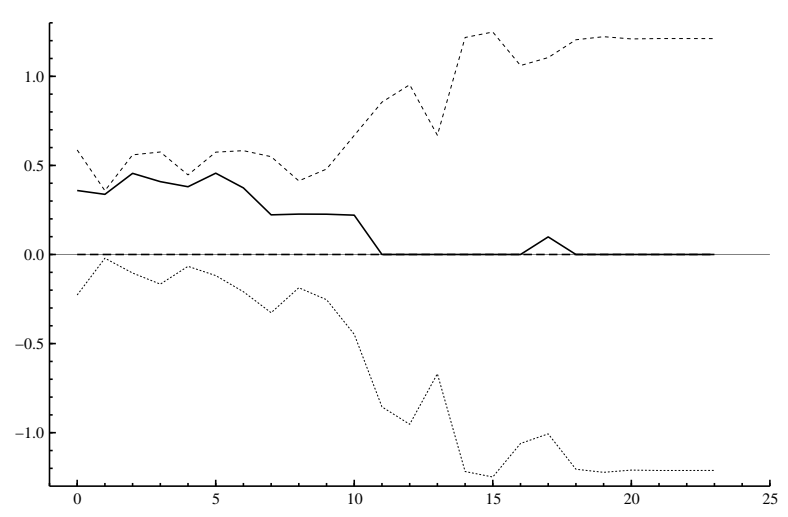

(e) Thailand

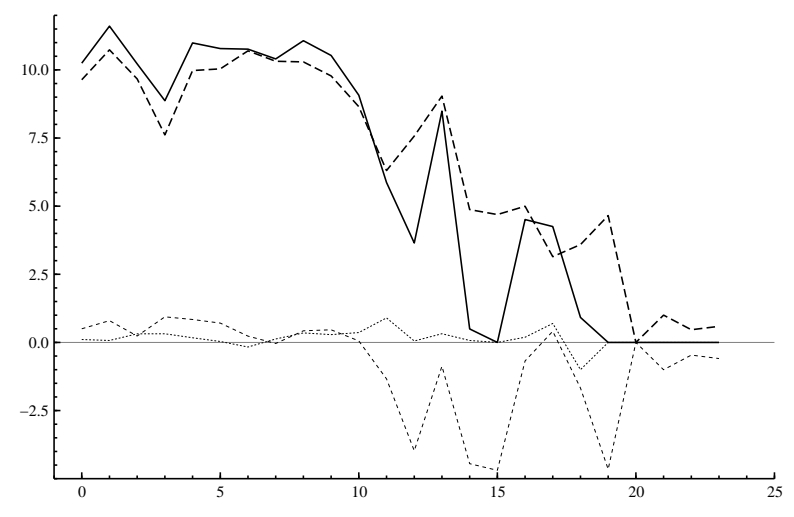

(b) EU

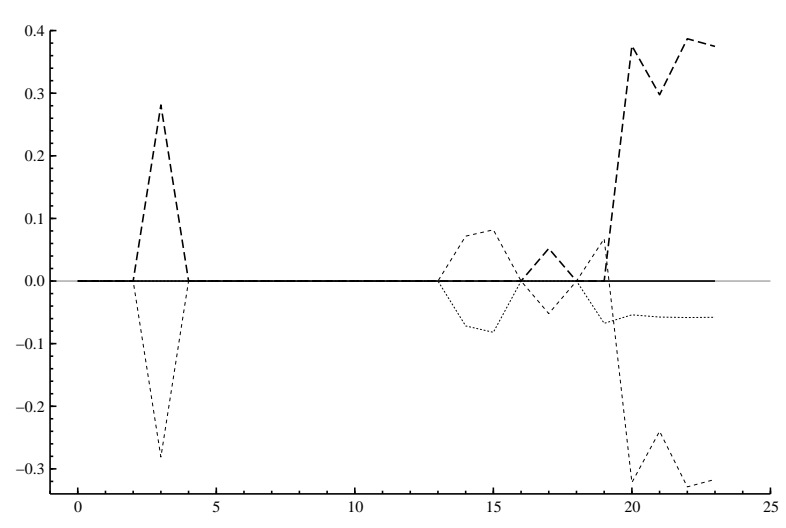

(d) Hong Kong

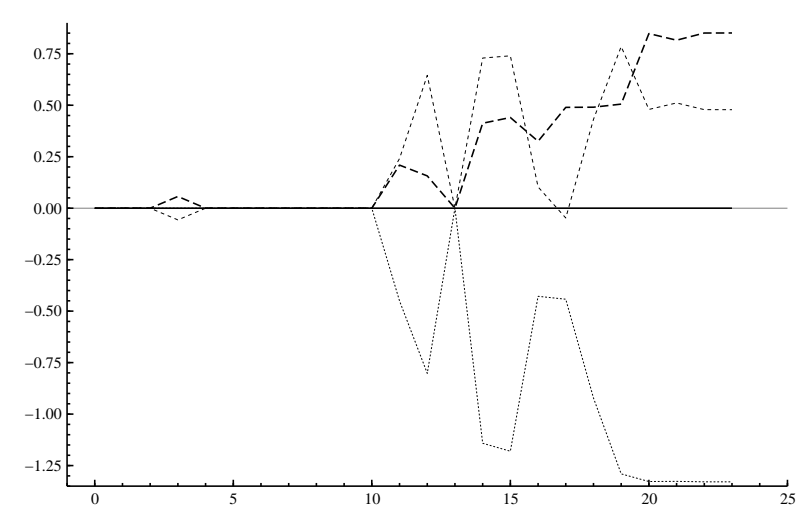

(f) Korea 


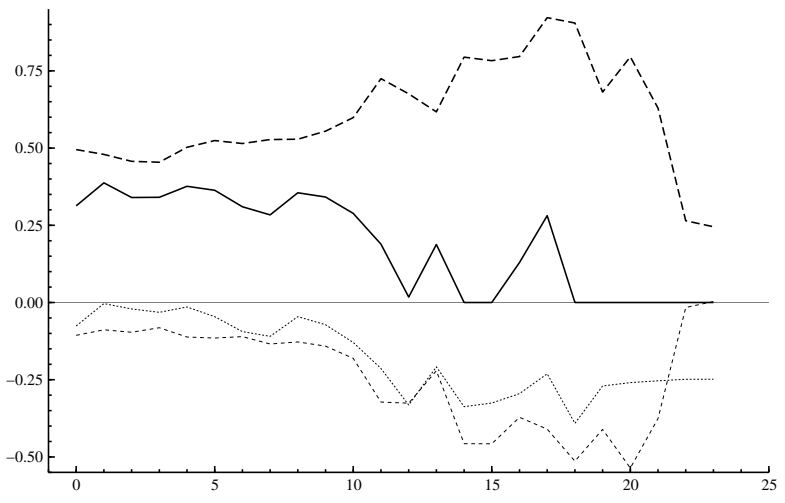

(g) Brazil

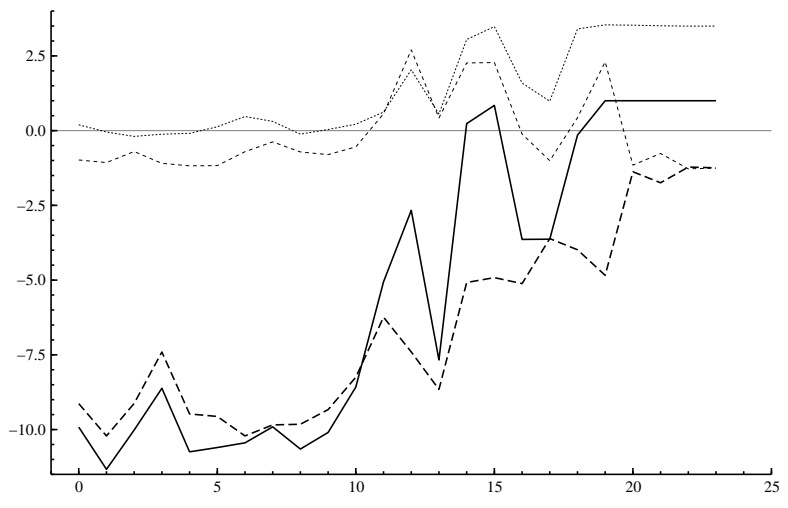

(h) risk free asset

Figure 4: The proportion invested in the different countries for the crisis conscious and crisis ignorant strategy and a decomposition of the differences for each trading day (numbered consecutively) in October 1997 assuming that short sales are not allowed. We assume the investor has a $\log$ utility function. The portfolios are based on the estimates in Tables 2 and 3 and the inferences presented in Figure 1. The portfolio differences between the two portfolios are decomposed in an estimation and a crisis effect. 